\title{
II. Der österreichische „Kurzvertrag” vom 13. März 1952 und die deutsche Frage
}

\author{
„Nicht die Aufmerksamkeit [...] hinsichtlich der deut- \\ schen $[\ldots]$ Frage schwächen"
}

Die unscheinbare Österreichfrage war im frühen Kalten Krieg für die Großmächte in hohem Maß ein Testfeld, um weiterreichende Absichten der Gegenseite auszuloten. Im Jahr 1949 ergab sich erstmals die reelle Möglichkeit eines Abzugs der alliierten Besatzungstruppen aus Österreich. Nach dem Bruch Titos mit Stalin Mitte 1948 war das vorgeblich größte Hindernis für den Abschluss des österreichischen Staatsvertrages, die Frage der österreichisch-jugoslawischen Grenze, auf der Tagung in Paris aus dem Weg geräumt worden. Die UdSSR unterstützte die jugoslawischen Gebietsansprüche, die sich zuletzt auf ein kleines Gebiet in Kärnten beschränkt hatten, nicht mehr. ${ }^{1}$ Der österreichische Staatsvertrag, über den man seit 1947 verhandelt hatte, wäre beinahe unter Dach und Fach gebracht worden. Am 20. Juni 1949, dem letzten Konferenztag des in Paris zusammengetretenen Rates der Außenminister, verlautbarten die vier Großmächte, den österreichischen Staatsvertrag bis zum 1. September unterschriftsreif machen zu wollen. Die Sonderbeauftragten für den österreichischen Staatsvertrag sollten die noch verbliebenen Artikel aushandeln. ${ }^{2}$ Die Sowjets trafen in der Folge in Österreich Maßnahmen, die bereits Zeitgenossen vermuten ließen, dass Stalin den Abschluss des Staatsvertrages ernsthaft anstrebte. Nachdem sich US-Präsident Truman am 26. Oktober 1949 endlich über die Bedenken des Verteidigungsministeriums hinweggesetzt und sein Einverständnis für den Abschluss des Staatsvertrages gegeben hatte, war es aber schon wieder zu spät. Zwei Tage zuvor, am 24. Oktober, hatte das Politbüro die sowjetischen Unterhändler angewiesen, die Verhandlungen bei der nächsten sich bietenden Möglichkeit abzubrechen. ${ }^{3}$ Wollte Stalin tatsächlich die sowjetische Besatzung Ostösterreichs 1949 aufgeben oder wollte er nur den Anschein erwecken, er meinte es ernst, um den Westen „nervös“ zu machen?4

\section{Österreich als Konsolidierungsfaktor des Ostblocks}

Der Kreml war im Herbst 1949 plötzlich, als hätte man es nicht früher gewusst, intern zur „Einsicht“ gelangt, dass ihn der Abschluss des Staatsvertrages im Weiteren des Rechtes zur Truppenstationierung in Ungarn und Rumänien berauben würde. Die offen zur Schau gestellte Zustimmungsbereitschaft der Westmächte (der US-Präsident hatte bis dahin aller-

\footnotetext{
${ }^{1}$ Karner/Ruggenthaler, „Eine weitere Unterstützung der jugoslawischen Gebietsforderungen bringt uns in eine unvorteilhafte Lage“.

2 Vgl. Stourzh, Um Einheit und Freiheit, S. 154f.; Cronin, Eine verpasste Chance?, S. 347-351.

${ }^{3}$ Siehe dazu im Detail meine Ausführungen in Ruggenthaler, Warum Österreich nicht sowjetisiert wurde, S.649-726; Karner/Ruggenthaler, Stalin und Osterreich, S. $120 \mathrm{f}$.

${ }^{4}$ Vgl. dazu Stalins Mitteilung an Pieck, in der er seine Zufriedenheit über die Reaktionen der Westmächte auf die Verhandlungen in Paris über Österreich zum Ausdruck brachte. Stalins „Einschätzungen“ zufolge hätten die Westmächte wegen „des Risiko[s], Frieden zu bekommen, [...] schon sehr nervös reagiert". Loth, Die Sowjetunion und die deutsche Frage, S.91.
} 
dings noch kein "grünes Licht“ gegeben!) ließ Stalin annehmen, der Westen beabsichtige mit einem solchen Schritt auch eine Unterstützung für Jugoslawien. ${ }^{5}$ Die daraufhin von der sowjetischen Seite verfolgte Junktimierung der österreichischen Frage mit der Triest-Frage und schließlich der deutschen Frage sowie die wiederholten Forderungen nach einer Entnazifizierung und Entmilitarisierung Österreichs torpedierten in der Folge jede Abschlussmöglichkeit des österreichischen Staatsvertrages. All dies musste „wiederholt für die Einbremsung der Staatsvertragsverhandlungen herhalten “.6 Für die 1950 anberaumten Sitzungen der Sonderbeauftragten gab Stalin keinen Verhandlungsspielraum. ${ }^{7}$ Er konnte aus zumindest zwei Gründen ab Herbst 1949 die sowjetische Besatzung Ostösterreichs nicht aufgeben: Neben der Paranoia Stalins, der die demonstrierte Bereitschaft der Westmächte, den österreichischen Staatsvertrag abschließen zu wollen, als politische Unterstützung für Tito interpretierte, ${ }^{8}$ bekam die Besatzung Ostösterreichs eine zunehmende Bedeutung für die Konsolidierung des Ostblocks, und zwar an zwei Flanken: für Ungarn und Rumänien sowie für die DDR. Auf der einen Seite hätte ein Abschluss des Staatsvertrages mit Österreich unmittelbar nach Gründung der DDR freilich viele Kräfte dazu ermuntern können, nach einer ähnlichen Lösung für Deutschland zu streben. Vielleicht war es gerade das, was Stalin wünschte: kein Abschluss mit Österreich, um sein eigentliches Ziel, die Konsolidierung der DDR, zu erreichen, andererseits jedoch den Anschein aufrechtzuerhalten, in der nebensächlichen österreichischen Frage verhandlungsbereit zu sein. Stalin war nicht ernsthaft an einer Umsetzung des Friedensvertrages mit Italien in Bezug auf die Triest-Frage (Einsetzung eines UN-Hochkommissars) interessiert. ${ }^{9}$ Triest war eine Trumpfkarte, die die UdSSR zu jeder Zeit zücken konnte, um den Vertrag mit Österreich nicht abschließen zu müssen und den Verbleib Ungarns und Rumäniens im sowjetischen Orbit nicht zu gefährden. ${ }^{10}$

Infolge der sich dahinschleppenden Staatsvertragsverhandlungen vertrat die KPÖ 1950 erstmals Neutralitätsparolen. ${ }^{11}$ Es ist eher unwahrscheinlich, dass die KPÖ dabei Rücken-

${ }^{5}$ Ruggenthaler, Warum Österreich nicht sowjetisiert wurde, S. 680.

"Bischof, Karl Gruber und die Anfänge des "Neuen Kurses" in der österreichischen Außenpolitik 1952/53, S. 144; Stourzh, Um Einheit und Freiheit, S.178. In den Pariser Vorverhandlungen der stellvertretenden Außenminister hatte sich Gromyko an die Devise des Politbüros zu halten, derzufolge er im Falle des Einbringens der Österreichfrage als eigenen Punkt für die Außenministerkonferenz durch die Westmächte auf der Erörterung der Triest-Frage als Tagesordnungspunkt zu bestehen hatte. RGASPI, f. 17, op. 162, d. 45, S. 187 und 213f.; ebd., op. 163, d. 1580, S. 141, Politbüro-Beschluss 89 (81-op) vom 28.3.1951.

${ }^{7}$ Ruggenthaler, Warum Österreich nicht sowjetisiert wurde, S. 683-685.

8 Ebd.

${ }^{9}$ Triest und sein „Hinterland“ Istrien waren seit 1945 Streitpunkt zwischen Jugoslawien, Italien und den Westalliierten. 1945 zog Tito seine Truppen aus Triest erst nach der Zusicherung der Westmächte, die Triester Frage auf Verhandlungsweg zu lösen, zurück. Der Friedensvertrag mit Italien sah in seinen Bestimmungen für Triest die Einsetzung eines UN-Hochkommissars vor. Nach dem Bruch Titos mit Stalin und der Annäherung Jugoslawiens an den Westen wurde die Triest-Frage unter Ausbootung der Sowjetunion entschieden. Triest wurde Italien zugeschlagen, Istrien Jugoslawien. Die UdSSR hatte in der Folge bei den Verhandlungen um den österreichischen Staatsvertrag ein völkerrechtlich überzeugendes Argument. Der Verweis auf einen möglichen Vertragsbruch der Westmächte in der Österreichfrage bot der UdSSR ab 1949/50 eine ideale Möglichkeit, Staatsvertragsverhandlungen nicht zuzustimmen. Zu Triest siehe Stourzh, Um Einheit und Freiheit, S. 178f. Zur Triest-Frage 1945 siehe insbesondere Gibianskij, Stalin i triestskoe protivostojanie 1945g.

${ }^{10}$ Ruggenthaler, Warum Österreich nicht sowjctisiert wurde, S. 686.

1 Siehe dazu Stourzh, Um Einheit und Freiheit, S. 267; Karner/Ruggenthaler, Stalin und Österreich, S. 124f. 
deckung aus Moskau hatte. Der erste Vorstoß in Richtung Neutralität dürfte vom sowjetischen Politvertreter, Michail Koptelov, und dem späteren stellvertretenden Hochkommissar in Österreich, Georgij Cinev, initiiert worden sein. Sie beide hatten zu dieser Zeit einen „Lösungsvorschlag der österreichischen Frage“ im sowjetischen Außenministerium eingebracht, demzufolge Österreich verpflichtet werden sollte, „keinem militärisch-politischem Block beizutreten “. ${ }^{12}$ Der Leiter der auch für Österreich zuständigen Dritten Europäischen Abteilung des sowjetischen Außenministeriums, Michail Gribanov, der nach Wilfried Loth so vehement 1951/52 für eine Neutralisierung Deutschlands eingetreten sein soll, ${ }^{13}$ reagierte jedoch ablehnend, weil derartige Verpflichtungen „in gewissem Maße eine diskriminierende Haltung gegenüber Österreich“ bedeuten würden und die Westmächte zum Schluss kommen könnten, dass die UdSSR eine "große Unruhe“ angesichts der entstehenden NATO ergreife. ${ }^{14}$ Beachtenswert ist die Wortwahl Gribanovs. Im Friedensvertragsvorschlag in der Stalin-Note vom 10. März 1952 sollte Deutschland sehr wohl verpflichtet werden, "keinerlei Koalitionen oder Militärbündnisse einzugehen “. ${ }^{15}$

Im Hinblick auf die deutsche Frage bleibt festzuhalten, dass Moskau 1950/51 in der Österreichfrage formell zwar gesprächsbereit blieb, inhaltlich jedoch keine Fortschritte wünschte. ${ }^{16}$ Im Januar 1952 fiel schließlich auch für lange Zeit die Gesprächsbereitschaft weg. Der sowjetische Vertreter in London wiederholte gegenüber den Westmächten programmgemäß die alten sowjetischen Forderungen und erklärte, ${ }^{17}$ an der für den nächsten Tag, dem 21.Januar, anberaumten Sitzung der Sonderbeauftragten nicht teilnehmen zu

12 AVP RF, f. 66, op. 29, p. 49, d. 11, S. 25-27, Gribanov an Vyšinskij zu den Vorschlägen Cinevs und Koptelovs, 28.2.1950 (Dokument 51).

${ }^{13}$ Loth, Die Entstehung der „Stalin-Note“. Das Zurückweisen dieser ersten quellenmäßig belegbaren, sowjetintern diskutierten „Neutralisierungsvorschläge“ durch Gribanov zeigt zudem, dass Gribanov in keiner Weise in Entscheidungsprozesse der sowjetischen Österreichpolitik involviert war, ebenso wenig der Apparat des sowjetischen Hochkommissars in Wien. Im Oktober 1949 hatte Stalin die Staatsvertragsverhandlungen abbrechen lassen. Er war zu diesem Zeitpunkt nicht zur Aufgabe der sowjetischen Besatzung Ostösterreichs bereit. Anfang 1950 schlug der stellvertretende sowjetische Hochkommissar „Lösungsvorschläge“ für die Österreichfrage vor. Hätte Gribanov die Position Stalins gekannt, hätte er die Vorschläge nicht mit inhaltlichen Begründungen zurückweisen müssen, die im Vergleich zur ein Jahr später gestarteten „Initiative“ in der Deutschlandfrage geradezu äußerst bizarr erscheinen. Österreich sollte durch Bündnisfreiheit nicht diskriminiert werden, Deutschland ein Jahr später sehr wohI! Die wesentlichste Rolle in der sowjetischen Österreichpolitik nach Stalin spielten Gromyko und Molotov. Ihre Vorschläge in der Österreichfrage wurden generell von Stalin angenommen. Freilich handelten sie nach seinen Prämissen und im Einklang seiner prinzipiellen Zielvorgaben. Neben den Politbüromitgliedern dürften nur Vyšinskij als Außenminister, sein Stellvertreter Zorin und Zarubin als Sonderbeauftragter für die Staatsvertragsverhandlungen über interne Denkweisen der sowjetischen Führung im Hinblick auf die Österreichpolitik involviert gewesen sein. Siehe dazu Ruggenthaler, Warum Österreich nicht sowjetisiert wurde.

${ }^{14}$ AVP RF, f. 66, op. 29, p. 49, d. 11, S. 25-27, Gribanov an Vyšinskij zu den Vorschlägen Cinevs und Koptelovs, 28.2.1950 (Dokument 51).

15 Ebd. Die Übernahme dieser zentralen Forderung der Neutralistenbewegung empfahlen im Februar 1951 Čujkov und Semenov. Siehe dazu Kapitel I.

${ }^{16}$ In einem Entwurf über die weitere Vorgehensweise in der Österreichfrage für Stalin ging Gromyko davon aus, „dass wir zum jetzigen Zeitpunkt an einer Beschleunigung des Abschlusses des österreichischen Vertrages nicht interessiert sind“. RGASPI, F 82, op. 2, d. 1115, S. 38, Gromyko an Stalin, Entwurf für Molotov, Januar 1952. Das fertiggestellte Dokument erging nach mehreren Korrekturen durch Molotov am 16.1.1952 an Stalin und beinhaltete nur mehr die weitere diplomatische Strategie. Ebd., S. 62-64. Hierzu genauer in Ruggenthaler, Warum Österreich nicht sowjetisiert wurde, S. 698f.

17 Siehe hierzu den entsprechenden Politbüro-Beschluss vom 17.1.1952, RGASPI, f. 17, op. 162, d. 48, S. 13 und 63f. (Dokument 54). 
können. In einer Note beschuldigten die Westmächte die UdSSR, den Abschluss des österreichischen Staatsvertrages seit zwei Jahren zu blockieren. Der Kreml antwortete darauf nicht einmal und gab monatelang offiziell keine Stellungnahme mehr zu Österreich ab. Dies geschah just in jenen Wochen, in denen er angeblich Gesprächsbereitschaft hinsichtlich Deutschlands bekundete und geradezu enthusiastisch Pläne für dessen Neutralisierung geschmiedet haben soll.

An dieser Stelle sei zudem darauf verwiesen, dass jedoch nicht der Tod Stalins der Wendepunkt in der sowjetischen Österreichpolitik war, ${ }^{18}$ sondern eine Neutralisierung Österreichs unter gewissen Umständen unter Stalin möglich gewesen wäre. ${ }^{19}$ Spätestens mit der Konsolidierung der DDR war der Weg dazu aus sowjetischer Sicht frei. An der Südostflanke hatte sich nichts geändert. Im Gegenteil, Tito wurde von den Westmächten noch stärker hofiert. Berichte über NATO-Pläne mit Jugoslawien, die Zusicherung Titos an die Amerikaner, im Kriegsfall mit der UdSSR Militärbasen in Jugoslawien zur Verfügung zu stellen und angebliche Kriegsvorbereitungen Jugoslawiens gegen die UdSSR und die „Länder der Volksdemokratie“, ${ }^{20}$ aber auch Absichten der NATO im Hinblick auf Dänemark und besonders Norwegen ließen in Moskau die Alarmglocken schrillen. ${ }^{21}$ Als Aufmarschgebiet gegenüber Jugoslawien wäre Ostösterreich weiter vonnöten gewesen, dennoch - und hierzu gab es bislang lediglich Hinweise ${ }^{22}$ - war eine (militärische) Neutralisierung Österreichs nunmehr, nach der Konsolidierung der DDR infolge der „Notenschlacht“ 1952, möglich und

${ }^{18}$ Diesen Standpunkt vertritt auch Gerald Stourzh. Siehe zuletzt Stourzh, Der österreichische Staatsvertrag in den weltpolitischen Entscheidungsprozessen, S.973f. Wolfgang Mueller ist dagegen anderer Meinung. Siehe Mueller, Gab es eine verpasste Chance?, S. 116.

${ }^{19}$ Chruščev verwies darauf in der Schlussrede der Plenartagungen des ZK der KPdSU im Juli 1955. Er erinnerte daran, dass bereits Stalin etwa ein Jahr vor seinem Tod mehrmals gefragt habe, warum der Vertrag mit Österreich nicht abgeschlossen werde. Stourzh, Um Einheit und Freiheit, S. 458f.; CWIHP, Nr. 10, S. $42 \mathrm{f}$.

20 RGASPI, f. 82, op. 2, d. 1374, S. 169-214. Politbericht der sowjetischen Botschaft in Belgrad über das 3. Quartal des Jahres 1951. Gromyko übersandte den Bericht am 11.1.1952 Stalin. Dem Politbericht zufolge war "die Politik der jugoslawischen Regierung in diesem Zeitraum nach wie vor auf die Vorbereitung Jugoslawiens an einem Krieg gegen die UdSSR und die Länder der Volksdemokratie ausgerichtet“. „Dies drückte sich insbesondere“, so der Bericht, „in der weiteren Militarisierung des Landes, in den Versuchen der Festigung des faschistischen administrativen Staatsapparates, der Armee und Poliz.ei aus."

21 RGASPI, f. 82, op. 2, d. 1043, S. 198, Berichterstattung Zorins an Stalin und alle Mitglieder des Achterkollegiums sowie an Suslov, Vyšinskij, Grigor'jan, Bogomolov und Puškin, 5.6. 1952 (Dokument 65); cbd., S. 248, Berichterstattung Tugarinovs an Malenkov, Bulganin, Vyšinskij und Vasilevskij, 11.7. 1952 (Dokument 120); ebd., S. 360, Berichterstattung Ignat'evs an Malenkov, Berija und Bulganin, 4. 10.1952. Zwei Analysen der KI gleichen Inhalts über die NATO-Pläne mit Nordeuropa vom 23.8. und 24.11.1952 finden sich bei Zubok, Soviet Intelligence and the Cold War, S. 458. Im Falle Dänemarks gelang es dem Kreml, keine US-Luftstützpunkte zuzulassen. Mastny, Die NATO im sowjetischen Denken und Handeln, S. 419. Besonders dic Position Norwegens erregte im Kreml aufgrund der gemeinsamen Grenze Unruhe. Nach der Aufnahme Griechenlands und der Türkei in die NATO verstärkte der Kreml seine Bemühungen, einen Beitritt Jugoslawiens zu verhindern. Egorova, NATO i evropejskaja bezopasnost', S. 299, 302 und 309. Auf der Berliner Außenministerkonferenz sah sich Österreich mit der sowjetischen Forderung nach Militärstützpunkten konfrontiert. Siehe dazu Stourzh, Um Einheit und Freiheit, S. 301-319.

22 Stourzh, Der österreichische Staatsvertrag in den weltpolitischen Entscheidungsprozessen, S.973f. Inwieweit die militärische Neutralisierung Österreichs 1955 auch einem politischen Entgegenkommen der neuen Kremlführung im Versöhnungsprozess mit Tito entgegenkam, gilt es noch zu erforschen. Nach einem Zeugnis Bruno Kreiskys soll Belgrad als Bedingung für eine Aussöhnung die Lösung der Österreichfrage an erste Stelle gesetzt haben. Ebd., S.979f. 
aus der Sicht des Kremls vorteilhaft. Möglich deshalb, weil die deutsche Frage „gelöst“ war und Stalin nach dem Bruch mit Tito das Interesse an Italien verloren hatte. ${ }^{23}$ Infolgedessen war auch eine Besatzung Österreichs nicht mehr von primärer Bedeutung. Ungeklärt bleibt allerdings weiterhin der Einfluss Molotovs im Kreml in dieser Frage, der sowohl vor als auch nach Stalins Tod gegen eine Neutralisierung Österreichs auftrat. Die Gründe hierfür dürften einerseits die Notwendigkeit einer Besatzung Österreichs als Druckmittel gegen Tito sein, andererseits in Molotovs Überzeugung zu sehen sein, die Westmächte strebten eine analoge Lösung zu Deutschland mittels eines separaten Vertrages mit Österreich an. ${ }^{24}$

Die Vorteile einer Neutralisierung Österreichs lagen freilich bereits auch vor Stalins Tod auf der Hand. Es galt, und dies waren die wichtigsten Motive für den Abschluss des Staatsvertrages 1955, einen „Anschluss“ Österreichs bzw. des Westteils des Landes an Deutschland und folglich die Einbindung in die NATO zu verhindern. Die Spaltung der NATO durch einen neutralen Keil in Mitteleuropa (Schweiz und Österreich) stellte für den Kreml zudem ein angenehmes „Nebenprodukt“ dar. ${ }^{25}$ Molotov musste schlussendlich dem Druck Nikita Chruščevs und Anastas Mikojans nachgeben. Ab 1949 hatte der Kreml die Österreichfrage mit der Triestfrage junktimiert, nach einem Zeugnis Mikojans infolge der sich verschärfenden internationalen Lage, die einen Abzug aus Österreich unmöglich machte. Molotov war den Erinnerungen Chruščevs zufolge auch noch nach der Lösung der Triestfrage zwischen Italien und Jugoslawien gegen eine Freigabe Ostösterreichs, ${ }^{26}$ vermutlich wegen seiner unveränderten Haltung zu Tito. In der Deutschland- und Österreichpolitik waren die Ziele vor und nach dem Tod Stalins dieselben geblieben. Mit der Neutralisierung Österreichs sollte ein neuer „Anschluss“ verhindert werden, und damit eine Stärkung Westdeutschlands. Nicht zuletzt hatte sich Molotov bei der Unterzeichnung des österreichischen Staatsvertrages am 15. Mai 1955 an die Direktive zu halten, über die deutsche Frage keine Verhandlungen mit den westlichen Außenministern zu führen. ${ }^{27}$ An diese Direktive hielt er sich wohl widerstandslos, sie war in seinem Sinne, im Gegensatz zur Freigabe Ostösterreichs, auch wenn er mit sachlichen Argumenten überzeugt worden sein soll. ${ }^{28}$

\section{Die Österreichfrage als Spielkarte der Weltpolitik}

Drei Tage nach der Stalin-Note unternahmen die Westmächte eine scheinbare „Initiative“ in der Österreichfrage. Am 13. März 1952 unterbreiteten sie der sowjetischen Seite einen neuen Vorschlag, den sogenannten Kurzvertrag. ${ }^{29}$ Diesem Vorschlag zufolge sollten sich die

${ }^{23}$ Zaslavskij, Lo stalinismo e la sinistra italiana dal mito dell'Urss alla fine del comunismo.

${ }^{24}$ Letztere Auffassung vertritt Zubok. Vgl. Zubok, Soviet Intelligence and the Cold War, S. 458 und 460 .

${ }^{25}$ Mastny, Die NATO im sowjetischen Denken und Handeln, S. 440f.; Thoß, NATO-Strategie und nationale Verteidigungsplanung, S. 258 und 278.

26 Stourzh, Um Einheit und Freiheit, S. 454-456.

${ }^{27}$ Stourzh, Um Einheit und Freiheit, S. 478; zuletzt ders., Der österreichische Staatsvertrag in den weltpolitischen Entscheidungsprozessen, S.990f.

28 So Mikojan am Juli-Plenum der KPdSU. Siehe dazu das Stenogramm der Juli-Plenarsitzung des ZK der KPdSU. Abgedruckt in Karner/Stelzl-Marx/Tschubarjan (Hrsg.), Die Rote Armee in Österreich, S. 841-843.

${ }^{29}$ Zum Kurzvertrag (Dokument 58) siehe generell die zahlreichen Arbeiten von Günter Bischof. Unter Berücksichtigung des Standes der Forschung zuletzt Bischof, „Recapturing the Initiative“ and „Negotiating from Strength“, S.217-247 und die dort zitierte Literatur. Die sowjetischen Akten (Politbüro- 
vier Besatzungsmächte verpflichten, Österreich innerhalb von 90 Tagen nach Inkrafttreten zu räumen (daher auch „Räumungsprotokoll“ genannt). Alle bisher ungelösten Verhandlungspunkte fanden im „Kurzvertrag“ keine Erwähnung mehr. Die „Initiative“ der Westmächte, vehement von Washington betrieben, diente jedoch allem ,anderen als österreichischen Zwecken “. ${ }^{30}$ Was für die Öffentlichkeit zunächst als unmittelbare Reaktion auf die sowjetische "Initiative“ in der deutschen Frage erscheinen mochte, war allerdings von langer Hand vorbereitet worden. Die Konferenz der Außenminister der USA, Großbritanniens und Frankreichs in Washington vom 12. bis 14. September 1951 hielt im Schlusskommuniqué fest, es gebe keinen Grund für eine weitere Verzögerung in der Frage des österreichischen Staatsvertrages. ${ }^{31}$ Wenige Tage später lag dem österreichischen Botschafter in Washington ein Entwurf eines im US-Außenamt vorbereiteten gekürzten Staatsvertrages vor. In einer ersten Analyse kam Botschafter Kleinwächter bereits zu dem Schluss, dass die Sowjets diesen Vorschlag wohl kaum annehmen könnten. Er erkannte bereits, dass der eigentliche Hintergrund der neuen Initiative der Westmächte die deutsche Frage war. ${ }^{32}$

Der Präsentation des „Kurzvertrages“ vorangegangen war die vorerst letzte Ladung zu einer Sitzung der Sonderbeauftragten für die Verhandlungen zum österreichischen Staatsvertrag im Januar 1952. ${ }^{33}$ Dem sowjetischen Außenamt und Molotov war, obwohl das MGB über diesbezügliche Informationen verfügte, nicht bekannt, dass die Westmächte bereits einen neuen Schachzug mittels des „Kurzvertrages“ planten. MGB-Chef Ignat'ev berichtete in dieser Phase Molotov und Gromyko in der Österreichfrage lediglich über die Gespräche des US-Sonderbeauftragten für den österreichischen Staatsvertrag, Samuel Reber, mit den drei Hochkommissaren in Wien. ${ }^{34}$ Den Inhalt der Gespräche entnahm das MGB der Berichterstattung des französischen Hochkommissars an sein Außenministerium. Reber selbst würde „sehr weit" gehen und den Sowjets entgegenkommen, doch die US-Regierung habe sich in der Österreichfrage noch nicht endgültig festgelegt, sie werde jedoch jegliche sowjetische Vorschläge zurückweisen, die „neuen Zugeständnissen“ seitens der USA gleichkämen. Die Hochkommissare hätten, so Ignat'ev, Übereinkunft darüber erzielt, „besser diesen Vertrag zu unterzeichnen“, sprich die Besatzung Österreichs zu beenden, als den gegenwärtigen Zustand aufrechtzuerhalten. ${ }^{35}$ Gromyko wurde darüber am 9.Januar in Kenntnis gesetzt. Er hatte bei den Vorbereitungen zur von den USA anberaumten Sitzung der Sonderbeauftragten für den österreichischen Staatsvertrag davon auszugehen, dass die Westmächte gegebenenfalls zum Abschluss des österreichischen Staatsvertrages bereit wären.

\footnotetext{
Beschlüsse aus der „Sondermappe“ und dem Molotov-Bestand zu Österreich) wurden zum „Kurzvertrag“ erstmals ausgewertet in meiner Darstellung in Ruggenthaler, Warum Österreich nicht sowjetisiert wurde, S. 698-701.

${ }^{30}$ Gehler, Kurzvertrag für Österreich?, S. 253; Stourzh, Um Einheit und Freiheit, S. 184-192.

31 Gehler, Kurzvertrag für Österreich?, S. 244.

32 Ebd.

${ }^{33}$ Vgl. Stourzh, Um Einheit und Freiheit, S. 183.

${ }^{34}$ Aufgrund der Tatsache, dass das sowjetische Außenamt und das Politbüro nachweislich nicht über den „Kurzvertrag“ informiert waren, kann man den Schluss ziehen, dass die Berichterstattungen des MGB an Molotov zumindest in den die Politik gegenüber Österreich betreffenden Fragen über Vollständigkeitscharakter verfügen. Siehe RGASPI, f. 82, op. 2, d. 1041, 1042, 1043. In den Akten selbst sind alle Seiten zugänglich; eine wie in allen anderen Staaten übliche Vorauswahl dürfte sicherlich stattgefunden haben, im Falle Österreichs ist eine solche in Bezug auf die Politik jedoch nicht auszumachen.

35 RGASPI, f. 82, op. 2, d. 1042, S.7, Berichterstattung Ignat'evs an Gromyko, 9.1.1952 (Dokument 53).
} 
Eine Woche später wandte sich Gromyko mit einem an Stalin adressierten Entwurf an Molotov: „Davon ausgehend, dass wir zum jetzigen Zeitpunkt an einer Beschleunigung des Abschlusses des österreichischen Vertrages nicht interessiert sind " ${ }^{36}$ empfahl Gromyko als Bedingung zu einer Zustimmung zu einer weiteren Sitzung die Missachtung des italienischen Friedensvertrages durch die Westmächte bezüglich Triest und die Frage der Entnazifizierung und Entmilitarisierung zu erörtern. Gromyko ging davon aus, dass im Falle weiterer Verhandlungen die Westmächte alle Hindernisse für einen Abschluss des österreichischen Staatsvertrages aus dem Weg räumen würden, um letztlich der UdSSR die Schuld am Platzen der Verhandlungen aufzubürden. ${ }^{37}$ Der Kreml befand sich wahrlich in einer Zwickmühle. Das Politbüro erteilte daher eine Direktive, ${ }^{38}$ der zufolge der sowjetische Vertreter in London die sowjetischen Forderungen (Triest, Entnazifizierung, Entmilitarisierung) wiederholte und erklärte, er könne an der für den 21.Januar 1952 anberaumten Sitzung der Sonderbeauftragten nicht teilnehmen. Der Kreml reagierte schließlich darauf, wie oben bereits erwähnt, gar nicht mehr. ${ }^{39}$ Es bedurfte also nicht des „Kurzvertrages“, um von westlicher Seite den Sowjets Munition und Vorwände zu liefern, die Verhandlungen der Sonderbeauftragten in der Österreichfrage Anfang 1952 endgültig abzubrechen. Moskau war nicht bereit, über Österreich zu reden.

Der im Sommer 1951 vom „Austrian Desk“ des State Department ausgedachte „abbreviated treaty "40 stieß in österreichischen Diplomatenkreisen sowie auch in London und Paris auf Unbehagen, man fürchtete negative sowjetische Reaktionen. ${ }^{41}$ Auf der NATO-Tagung in Lissabon im Februar 1952, auf der die Aufnahme Griechenlands und der Türkei in die NATO beschlossen wurde, erreichte die französische Seite noch die Einbringung eines expliziten Anschlussverbots Österreichs. ${ }^{12}$ Die Franzosen waren von Anfang an bemüht, die Sowjets wissen zu lassen, dass ihre Zustimmung zum „Kurzvertrag“ nur unter dieser Bedingung erfolgt sei und dass den Sowjets der Weg zurück an den Verhandlungstisch jederzeit offenstehen sollte. Zwischen dem 29. Februar und 15. März 1952 sollte schließlich dex „Kurzvertrag“ in Moskau deponiert werden. Die Österreicher mussten sich wohl oder übel mit dem Vorschlag einverstanden erklären und die drei Westmächte gaben sich demonstrativ einig. ${ }^{43}$ Mit dem „Kurzvertrag“wollte allen voran Washington die sowjetischen Absichten in der deutschen Frage „prüfen“. Die Amerikaner erhofften sich damit, im Falle einer Ablehnung des Kurzvertrages durch Moskau die „mangelnde Ernsthaftigkeit der Deutschland-

${ }^{36}$ Ruggenthaler, Warum Österreich nicht sowjetisiert wurde, S.698; RGASPI, f. 82, op. 2, d. 1115, S.62-64, Gromyko an Stalin, 16.1.1952. Entwürfe mit Ausbesserungen Molotovs, ebd., S.38f. und S. $67-69$.

${ }^{37}$ Ebd. Bereits im Spätsommer 1951 hatte das sowjetische Außenministerium vernommen, Washington habe die Absicht, die Verhandlungen über den österreichischen Staatsvertrag wieder aufzunehmen, und werde Österreich bei der Lösung der Schuldenfrage mit der UdSSR finanzielle Hilfe leisten. RGASPI, f. 82, op. 2, d. 1041, S. 153, Berichterstattung Zorins an Gromyko, 1.8.1951 (Dokument 52). ${ }^{38}$ RGASPI, f. 17, op. 162, d. 48, S. 13 und 63f., Politbüro-Beschluss P 85 (283-op) vom 17.1.1952 (Dokument 54).

${ }^{39}$ Ruggenthaler, Warum Österreich nicht sowjetisiert wurde, S. 699; Stourzh, Um Einheit und Freiheit, S. 183.

40 Bischof, Austria in the First Cold War, S. 123-129; Bischof, Karl Gruber und die Anfänge des „Neuen Kurses" in der österreichischen Außenpolitik 1952/53, S. 146.

${ }^{41}$ Gehler, Kurzvertrag für Österreich?, S. 248f.

42 Bischof, Karl Gruber und die Anfänge des „Neuen Kurses“ in der österreichischen Außenpolitik 1952/53, S. 147; zuletzt Bischof, „Recapturing the Initiative“ and „Negotiating from Strength", S. 243.

43 Gehler, Kurzvertrag für Österreich?, S. 248-250. 
vorschläge Stalins“ zu beweisen. Eine bizarr erscheinende Logik, ${ }^{44}$ aber wohl keine falsche. Der „Kurzvertrag“ war von langer Hand vorbereitet worden und nicht als Antwort auf die Stalin-Note zu verstehen. Er war ein reines Propagandainstrument bzw. sollte den Zweck verfolgen, „abzutesten“, inwieweit Stalin in der Deutschland-Frage gesprächsbereit war. Der „Kurzvertrag“" wurde allerdings so formuliert, dass der Westen sicher sein konnte, dass Moskau ihn von vornherein ablehnen würde. Er wurde von den Amerikanern gegen anfänglichen Widerstand der Briten und Franzosen durchgesetzt. Auf eine Neutralisierung Österreichs konnte sich der Kreml zu diesem Zeitpunkt (noch) nicht einlassen. Zudem sah der „Kurzvertrag“ja sogar die Option der freien Bündniswahl vor.

Am 10. März kam schließlich der Kreml dem Westen, ohne jedoch über dessen „Kurzvertrags"-Absichten informiert gewesen zu sein, ${ }^{45}$ mit der Stalin-Note und dem vermeintlichen Neutralisierungsangebot für Deutschland zuvor. Drei Tage später überbrachten die Botschafter der drei Westmächte im sowjetischen Außenministerium den „Kurzvertrag“.46

Der „Kurzvertrag“vom 13. März dürfte im Kreml zunächst für einige Irritationen gesorgt haben. Nicht anders ist es zu erklären, dass Valerijan Zorin erst am 19. März der sowjetischen Führung einen erklärenden Bericht darüber erstattete, was es mit dem „Kurzvertrag“ auf sich hatte. Erst jetzt - Hinweise über eine frühere Berichterstattung finden sich nicht und können, wie in der Folge zu zeigen sein wird, ausgeschlossen werden ${ }^{47}$ trug er Molotov vor, dass einer Note der französischen Botschaft in Washington an das französische Außenministerium vom 14. September 1951 zufolge auf der Konferenz der drei Außenminister der USA, Großbritanniens und Frankreichs am 13. September der amerikanische AuBenminister Acheson die Einbringung des „Kurzvertrages“ in die österreichischen Staatsvertragsverhandlungen vorgeschlagen hatte, um „die sowjetische Regierung in eine ,schwierige Lage‘ zu versetzen“. ${ }^{48}$ Die Molotov vorgetragene Analyse Zorins stützt den Verdacht, dass er erst jetzt, nach vermutlich gezielter Beauftragung des MGB, ${ }^{49}$ nach entsprechenden abgefangenen Informationen zu suchen bzw. bei „Vertrauenspersonen “ im französischen Außenministerium nachzufragen, ${ }^{50}$ vom „Kurzvertrag“ erfuhr. Er erklärte Molotov:

44 Ebd., S. 253.

45 Die sowjetische Führung war jedoch nicht nur in keiner Weise über die wahren Absichten des „Kurzvertrages“ informiert, es finden sich in sämtlichen, zur Verfügung stehenden Rapporten über die 9 . Tagung des NATO-Rates nicht einmal Meldungen darüber, dass die Westmächte „neue Vorschläge“ in der Österreichfrage öffentlich angekündigt hatten. $\mathrm{Zu}$ den Österreichberatungen in Lissabon siehe Bischof, Karl Gruber und die Anfänge des „Neuen Kurses“ in der österreichischen Außenpolitik 1952/53, S. $146 f$.

46 RGASPI, f. 82, op. 2, d. 1115, S. 95-109.

47 Auch in allen Berichterstattungen über die Lissabonner Tagung des NATO-Rates, auf der die Übermittlung des "Kurzvertrages“ an die UdSSR beschlossen wurde, ist keine Rede vom „Kurzvertrag“. RGASPI, f. 82, op. 2, d. 1042, S.58, Berichterstattung Zorins an alle Mitglieder des Achterkollegiums sowie an Vyšinskij, Vasilevskij, Gromyko und Grigor'jan, 2.3. 1952 (Dokument 47); RGASPI, f. 82, op. 2, d. 1170, S. 48-52, Gromyko an Stalin, Entwurf an Molotov, 3.3.1952 (Dokument 48); RGASPI, f. 82, op. 2, d. 1042, S. 77, Ignat'ev an alle Mitglieder des Achterkollegiums und Vyšinskij, 17.3.1952 (Dokument 80); RGASPI, f. 82, op. 2, d. 1042, S. 76, Ignat'ev an alle Mitglieder des Achterkollegiums und Vyšinskij, 17.3. 1952 (Dokument 81).

48 RGASPI, f. 82, op. 2, d. 1042, S. 82, Berichterstattung Ignat'evs an alle Mitglieder des Achterkollegiums sowie an Vyšinskij und Zorin, 19.3.1952 (Dokument 61).

49. Hiervon zeugt die oben genannte Analyse Zorins auf der Basis französischer Telegramme vom September 1951. Ebd.

50 Dies belegen Informationen aus den „Führungskreisen“ des französischen Außenministeriums vom 18. März 1952 (fünf Tage nach Übergabe des „Kurzvertrages“), wobei unklar bleibt, ob die Franzosen 
„Die Regierungen der Westmächte legten bei der Übergabe der Note zum Österreichvertrag Eile an den Tag: ihre Botschafter in Moskau versuchten beharrlich, einen Empfang im Außenministerium der UdSSR ausgerechnet am 13. März, also sofort nach der Veröffentlichung der sowjetischen Note über die Grundlagen eines Friedensvertrages mit Deutschland, zu erreichen. Mit ihrer Note zum Österreichvertrag versuchten die Westmächte, die Aufmerksamkeit der öffentlichen Meinung in der Welt von der neuen wichtigen Initiative der UdSSR in der deutschen Frage abzulenken. ${ }^{\text {"51 }}$ Mit diesem Wissen war Zorin nunmehr klar, dass die Westmächte geplant hatten, den „Kurzvertrag“ in die für den 21.Januar 1952 anberaumte Sitzung einzubringen. Im Januar 1952 war der sowjetischen Führung allerdings nichts vom „Kurzvertrag“ bekannt gewesen. Dies lässt sich aufgrund der Tatsache beweisen, dass, wie oben dargelegt, das sowjetische Außenministerium bei den internen Vorbereitungen für diese Sitzung davon ausgegangen war, dass „alle übrigen Artikel ausverhandelt werden könnten" und der österreichische Staatsvertrag unterschriftsreif sein würde.

\section{Schweigephase des Kremls zu Österreich}

Da der Kreml Anfang 1952 nicht am Abschluss des österreichischen Staatsvertrages interessiert war, ließ er seinen Sonderbeauftragten, wie erwähnt, zur anberaumten Sitzung erst gar nicht erscheinen. Das sowjetische Außenministerium wusste nichts von der geplanten Präsentation des „Kurzvertrages“ durch die Westmächte, d. h. das war nicht, wie früher oftmals vermutet, der Grund, warum die Sowjets nicht am Verhandlungstisch erschienen. Zu diesem Zeitpunkt war der Kreml generell an einem Abschluss des Staatsvertrages nicht interessiert. ${ }^{52}$ Die Briten kamen damals zu dem Schluss, dass die Sowjets vor dem geplanten diplomatischen Manöver des „Kurzvertrages“ gewarnt worden sein mussten. Indische Diplomaten hatten nämlich die Briten informiert, die Sowjets seien nicht zur Sitzung in London erschienen, um den Amerikanern nicht die Möglichkeit zu geben, den „Kurzvertrag“ zu präsentieren, sondern ihn als „unilateralen Akt der Westmächte“ erscheinen zu lassen. Dem war nicht so. Die indischen „Informationen“ waren nicht mehr als eigene Interpretationen der sowjetischen Politik. ${ }^{53}$

Auch wenn das MGB in der Frage des „Kurzvertrages“ eindeutig versagt und der sowjetischen Führung Ende 1951, Anfang 1952 nichts über das geplante westliche diplomatische Manöver des „Kurzvertrages“ berichtet hatte, war dies für die weitere Vorgehensweise des Kremls in der Deutschland- und Österreichpolitik nicht weiter tragisch. Moskau war zumindest bis zum Frühjahr 1952 ohnedies nicht bereit, Österreich zu „neutralisieren“. Noch stand einer „Neutralisierung“ Österreichs mindestens eine Frage im Weg, nämlich die deutsche. Hätte man sich über die „Neutralisierung“ Österreichs mit den Westmächten einigen können - und das wollte man nicht - hätte man ein Modell für Deutschland geschaffen. Nunmehr legte der Kreml in der Österreich-Frage, übrigens erstmals im Laufe der Staatsvertragsverhandlungen, nicht einmal mehr formale Gesprächsbereitschaft an den Tag.

von sich aus an die Sowjets herantraten, um sie über ihre Position bei der „Kurzvertrags“-Initiative $7 . u$ informieren. Siehe RGASPI, f. 82, op. 2, d. 1042, S. 78, 18.3.1952 (Dokument 59).

${ }^{31}$ RGASPI, f. 82, op. 2, d. 1042, S. 82, Berichterstattung Zorins an alle Mitglieder des Achterkollegiums sowie an Vyšinskij und Gromyko, 19.3.1952 (Dokument 61).

${ }^{52}$ Dazu ausführlicher in Ruggenthaler, Warum Österreich nicht sowjetisiert wurde, S. 698-701.

${ }^{53}$ Bischof, „Recapturing the Initiative“ and „Negotiating from Strength“, S. 242f. 
Zorin zog gegenüber Molotov den Schluss, dass ein Zurückweisen des „Kurzvertrages“ die Übergabe der Österreich-Frage an die UNO zur Folge haben könne. Er zog zudem in Betracht, die Westmächte könnten mit einer einseitigen Deklaration zu Österreich auftreten und mit dem Abzug ihrer Truppen aus den Besatzungszonen Österreichs beginnen, was zugleich den Abzug der sowjetischen Truppen aus Ostösterreich bedingen würde. ${ }^{54}$

Im Falle Deutschlands war dem Kreml klar, dass eine solche Variante von den Westmächten nicht ins Kalkül gezogen wurde. Alles in allem eine prekäre Lage für Moskau. In der Österreichfrage spielte der Kreml in der Folge auf Zeit, er konnte freilich auch nichts anderes tun. Man wusste nunmehr, dass der „Kurzvertrag“ keine direkte Antwort auf die StalinNote vom 10. März war, der Westen diesen allerdings dazu verwenden wollte, um die öffentliche Meinung von der deutschen Frage abzulenken. So war es für Moskau das Beste, auf den „Kurzvertrag“ erst gar nicht zu reagieren. Die Österreichfrage war zu gefährlich geworden. Hätte Stalin 1951/52 tatsächlich eine „Neutralisierung“ Deutschlands gewollt, hätte er die vermeintlich kleine Österreichfrage längst vom Tisch nehmen können. Günter Bischof wies bereits 1991 auf die bis dahin in der Historiographie nicht beachtete - und bis heute stark vernachlässigte - Interdependenz der sowjetischen Stalin-Noten mit der westlichen Note, die dem Kreml den Kurzvertrag präsentierten, hin. ${ }^{55}$ Die österreichische Frage konnte aus sowjetischer Sicht frühestens dann gelöst werden, wenn die Teilung Deutschlands unwiderruflich geworden war. ${ }^{56}$ Vorläufig aber musste Moskau aus seiner Sicht in der Österreichfrage noch künstlich Hindernisse produzieren, vor allem bei der Forderung nach Entnazifizierung und Entmilitarisierung und in der Triest-Frage. ${ }^{57}$

Nach fast zwei Monaten fragten die Westmächte am 9. Mai 1952 auf diplomatischem Weg im sowjetischen Außenministerium nach und baten „bei erstbester Möglichkeit den Standpunkt im Zusammenhang mit den Vorschlägen zur Österreichregelung mitzuteilen " ${ }^{58}$ Die Sowjets konnten auch jetzt noch keine Antwort darauf geben. Jede andere Antwort als eine positive wäre für alle Seiten überraschend gewesen. Moskau konnte zu dieser Zeit kein paralleles Neutralisierungs-,Angebot“ zu Österreich richten. Dies hätte freilich die zur Schau getragene Gesprächsbereitschaft in der deutschen Frage untermauert. Nach Erhalt der Urgenz vom 9. Mai wandte sich Vyšinskij drei Tage später an Stalin und empfahl, nicht die auf die Erörterung der deutschen Frage gerichtete Aufmerksamkeit zu schwächen: „Ich würde

${ }^{54}$ RGASPI, f. 82, op. 2, d. 1042, S. 82, Berichterstattung Zorins an alle Mitglieder des Achterkollegiums sowie an Vyšinskij und Gromyko, 19.3.1952 (Dokument 61).

52 Bischof, Karl Gruber und die Anfänge des „Neuen Kurses“ in der österreichischen Außenpolitik 1952/53, S. 147-149.

${ }^{56}$ Bischof, „Recapturing the Initiative“ and „Negotiating from Strength“, S. 219.

${ }^{57}$ Dem Kreml ging es dem Wesen nach weder um die Triester Frage, noch um Entnazifizierung oder Entmilitarisierung. Richtig eingeschätzt wurde dies bereits 1991 von Bischof, Karl Gruber und die Anfänge des „Neuen Kurses“ in der österreichischen Außenpolitik 1952/53, S. 144. Von Interesse ist diesbezüglich die von Gribanov vorgeschlagene weitere Vorgehensweise in der Österreichfrage ab Anfang 1950. Gribanov legte Argumente dar, mithilfe derer ein Abschluss des Staatsvertrages verzögert werden konnte. Wie der weitere Verlauf der Verhandlungen zeigt, nahm sich die sowjetische Diplomatie dieser Strategie an. AVP RF, f. 66, op. 29, p. 49, d. 11, S. 25-27, Gribanov an Vyšinskij, 28.2. 1950 (Dokument 51). Zur internen sowjetischen Positionierung und Vorbereitung auf die Staatsvertragsverhandlungen siehe Ruggenthaler, Warum Österreich nicht sowjetisiert wurde, S.698-705; Michael Gehler meinte diesbezüglich bereits 1994, Stalin hätte mit der Lösung der Österreichfrage die Chance gehabt, angebliche Gesprächsbereitschaft in der deutschen Frage zu untermauern, doch hätten dies die Westmächte mit ihrer starren Beharrung auf dem „Kurzvertrag“ erschwert. Gehler, Kurzvertrag für Österreich?, S. 277. Denselben Schluss zieht Zubok in seiner Abhandlung Soviet Intelligence and the Cold War, S. 452.

${ }_{58}$ RGASPI, f. 82, op. 2, d. 1115, S. 110, Vyšinskij an Stalin, 12.5. 1952 (Dokument 63). 
es für zielführend halten, im Grunde auf die Note [...] über einen Kurzvertrag für Österreich zum gegenwärtigen Zeitpunkt keine Antwort zu geben, um nicht die Aufmerksamkeit für die Erörterung der deutschen Frage, die, wie bekannt ist, auch die Regierungen der USA, Englands und Frankreichs anstreben, zu schwächen. "59

Besonders im Jahr 1952 wurde offensichtlich, dass Österreich ein Spielball der Weltpolitik im Kalten Krieg war. Der Westen wollte mit der Österreich-Frage Stalin daraufhin abtesten, ob er tatsächlich in der deutschen Frage gesprächsbereit war. Der Kreml wiederum erlegte sich das Gebot auf, über Österreich zu schweigen, um keine Modellfalllösung für Deutschland ins Spiel zu bringen. Österreich diente als Testobjekt, um die Absichten der jeweils anderen Seite herauszufinden. Die Westmächte hatten in ausreichendem Maße „ausgelotet", wozu Stalin bereit war und wie weit er gehen würde.

Die seit Ende 1945 demokratisch gewählten österreichischen Koalitionsregierungen aus ÖVP und SPÖ (bis Ende 1945 mit einem Drittel Kommunisten, bis 1947 mit einem KPÖMinister) wurden von den sowjetischen Politvertretern seit den Novemberwahlen 1945, bei denen die KPÖ mit knapp fünf Prozent Stimmenanteil ein desaströses Wahlergebnis einfuhr, als westliche Marionetten angesehen, die sich zusehends proamerikanisch entwickelten und mit lauter amerikanischen und britischen Agenten besetzt seien. ${ }^{60}$ Der "geheime Verbündete" 61 der Westmächte war in den Augen des Kremls keineswegs ein geheimer Partner des Westens, sondern offen gegen die Sowjetunion ausgerichtet. Die NATO-Erweiterung Anfang der 1950er Jahre wurde vom Kreml wohl mit großer Sorge beobachtet. ${ }^{62}$ Zumindest sowjetische Diplomaten zogen die Möglichkeit der Aufnahme Österreichs bzw. die Integration von Teilen Österreichs in die NATO in Betracht. ${ }^{63}$ Der sowjetische Hochkommissar in Österreich, Vladimir Sviridov, unterstützte 1952 daher auch noch nicht den Neutralisierungsgedanken im Hinblick auf Österreich. Anfang 1952, vor der endgültigen Konsolidierung der DDR, war dieser aus sowjetischer Sicht unvorteilhaft; man befürchtete, die Neutralisierung würde letztlich nicht nur zu einer Westorientierung des Landes, die ohnedies voll im Gang war, sondern auch zur militärischen Integration in der NATO münden. Sviridovs Meinung nach verhinderte dies jedoch die entschiedene Haltung der österreichischen Koalitionsregierung gegen eine Teilung des Landes, zu der es infolge der amerikanischen

59 Ebd., S. 110, Vyšinskij an Stalin, 12.5. 1952. Interessant in diesem Zusammenhang erscheint die Deutung des „Kurzvertrages“ in einem internen Tätigkeitsbericht des sowjetischen Hochkommissars Vladimir Sviridov an das ZK der KPdSU. Darin bezeichnete er den Kurzvertrag als amerikanisches „Manöver“, das den endgültigen Abbruch der Staatsvertragsverhandlungen zum Ziel hatte und „das Land vor die Perspektive einer langen Besatzung und einer möglichen Teilung “ führen sollte. Zweifelsohne war der Kurzvertrag gegen die Interessen der UdSSR gerichtet, doch das war für Vyšinskij in seinen Berichten an Stalin, wie oben dargelegt, nicht das entscheidende Argument. Vyšinskij empfahl Stalin sogar, den Erhalt der Vorschläge zum "Kurzvertrag" zu bestätigen. Ebd., S. 112.

60) Ruggenthaler, Warum Österreich nicht sowjetisiert wurde, S. 662.

${ }^{61}$ Diesen Ausdruck, dass Österreich „so etwas wie zum geheimen Verbündeten des Westens“ wurde, prägte Gerald Stourzh. Siehe dazu Bischof, Österreich - ein "geheimer Verbündeter" des Westens?, S. 425 .

62 RGASPI, f. 82, op. 2, d. 1041-1043 (Dokumente 65, 66, 71 und 120).

63 Zorin analysierte vor Molotov das Vorgehen der USA am Balkan „7um Zwecke der Festigung eines antisowjetischen Aufmarschgebietes am Mittelmeer" und schloss den Einschluss Italiens und Österreichs nicht aus. RGASPI, f. 82, op. 2, d. 1043, S. 198, Berichterstattung Zorins an Stalin und alle Mitglieder des Achterkollegiums sowie an Suslov, Vyšinskij, Grigor'jan, Bogomolov und Puškin, 5.6. 1952 (Dokument 65). Vgl. dazu auch die Berichte des KI an Stalin vom 23.8.1952, demzufolge die USA auch mit Österreich ein Separatabkommen anstrebten und das Land in die NATO integrieren möchten. Zubok, Soviet Intelligence and the Cold War, S. 458. 
militärischen Absichten mit Österreich gekommen wäre. Die Amerikaner, so Sviridov, beabsichtigten den Anschluss Westösterreichs an Bayern, was zu einer Stärkung Westdeutschlands und damit der Position der USA in Europa geführt hätte. Hier seien sie jedoch auf französischen und britischen Widerstand gestoßen. Zudem betonte Sviridov die strategische Bedeutung Westösterreichs für die Versorgung amerikanischer Truppen in Bayern von Triest aus. Er kam zu dem Schluss, dass „die USA die Frage des österreichischen Vertrages in der Absicht des Anschlusses des Territoriums Österreichs an den Atlantikblock und nicht auf der Grundlage seiner Neutralität oder Unabhängigkeit interessiert “ ${ }^{64}$

\section{Finnlandlösung für Österreich?}

Die österreichischen Diplomaten und Politiker hatten frühzeitig erkannt, dass Österreich zu einem Spielball der westlichen Deutschlandpolitik geworden war und der „Kurzvertrag“ allem anderen als österreichischen Zwecken diente. Wohl oder übel sah man sich dennoch genötigt, die westlichen „Vorschläge“ mitzutragen. Nachdem das österreichische Problem nach der Stalin-Note international völlig von der Bühne verschwunden war, sah man in Wien nur mehr den Ausweg, die lange gehegten Pläne der Übergabe der Österreichfrage an die UNO zu forcieren und umzusetzen, wenn auch in engster Fühlungnahme vor allem mit Washington. Dennoch begann sich nunmehr in Wien ein Kreis an Politikern, allen voran unter dem ÖVP-Vorsitzenden und späteren Bundeskanzler Julius Raab, herauszukristallisieren, der die unumstrittene Ausrichtung der österreichischen Außenpolitik auf die USA und die damit einhergehende offene Konfrontation mit der UdSSR angesichts des Stillstandes in der Österreichfrage ablehnte. Noch lange bevor Julius Raab im Juni 1953 seine berühmte Feststellung traf, dass es sinnlos sei, „wenn man dem russischen Bären, der mitten im österreichischen Garten drinnen steht, immer wieder durch laut tönende Sonntagsreden in den Schwanzstummel zwickt" ${ }^{65}$ sendete er bereits deutliche Signale nach Moskau. Am 23. Februar 1952, wenige Wochen nach dem ersten außerordentlichen Bundesparteitag der ÖVP („Parteitag der neuen Konzepte“), ${ }^{66}$ gab der ominöse Führer der „Demokratischen Union“ (DU), Josef Dobretsberger, 1947 als angeblicher sowjetischer Wunschkandidat für den Posten des österreichischen Bundeskanzlers im Zuge der „FiglFischerei“ kolportiert und aufgrund seiner Tätigkeit als "Sowjetsberger" abgestempelt, ${ }^{67}$ Raab zu verstehen, er müsse ein „zweiter Kekkonen“ werden und der Weg Österreichs „aufs

${ }^{64}$ RGASPI, f. 17, op. 137, d. 918, S. 74-201, hier S. 104, Bericht über die Arbeit des sowjetischen Teils der Alliierten Kommission und der politischen Vertretung der UdSSR in Österreich für das Jahr 1952, Wien, 29. 2. 1953, Sviridov und Kudrjavcev an das ZK der VKP(b), z. H. A. Smirnov.

6.5 Stourzh, Um Einheit und Freiheit, S. 225.

i6 Reichhold, Julius Raab als Bundesparteiobmann, S. 203. Zu ersten kritischen Stimmen innerhalb der ÖVP gegen die Parteiführung kam es nach der Bundespräsidentenwahl im Mai 1951. Die danach intern vorgebrachte offene Kritik an der Parteiführung führte schließlich zur „sukzessiven Übernahme der Parteiführung durch den Wirtschaftsflügel um Julius Raab“. Karner, Die Österreichische Volkspartei. Ein Abriss ihrer Entwicklung 1945-1995, S. 38.

67 Die in die Geschichte als einer der größten innenpolitischen Skandale der jungen Zweiten Republik eingegangenen geheimen Gespräche zwischen Ernst Fischer von der KPÖ und Bundeskanzler Figl („Figl-Fischerei“) wurden lange Zeit als sowjetischer Versuch gewertet, in Österreich die Regierung sowjetfreundlich umzubilden. Fischer handelte jedoch eigenmächtig, sogar ohne Rücksprache mit scinen Parteigenossen. Dobretsberger wurde zu dieser Zeit in sowjetischen Berichten noch als westlicher Spion bezeichnet. Siche dazu Ruggenthaler, Warum Österreich nicht sowjetisicrt wurde, S. 667-669. 
Haar genau mit dem Weg Finnlands zusammenfallen“. Raab bat daraufhin Dobretsberger, auf seiner bevorstehenden Reise zur Wirtschaftskonferenz nach Moskau Vertretern des sowjetischen Außenministeriums mitzuteilen, „dass es in der ÖVP eine Gruppe von Leuten gibt [...], die den Weg der Neutralisierung Österreichs suchen, ohne es hierbei in ein Land der Volksdemokratie umzuwandeln “. 68

Wer den Stein ins Rollen brachte, muss vorerst ungeklärt bleiben. In Bezug auf Skandinavien gab der Kreml den Finnen in dieser Zeit klar zu verstehen, dass er einer Neutralisierung skandinavischer Länder Gutes abgewinnen könnte. ${ }^{69}$ Schweden gab diesbezüglich sicherlich ein gutes Beispiel ab, auch wenn die sowjetisch-schwedischen Beziehungen infolge von Luftraumverletzungen, die der Kreml Stockholm vorwarf, in dieser Zeit schwer belastet waren. ${ }^{70}$

Es ist möglich, dass Dobretsberger im Falle Österreichs nicht selbst die Initiative ergriffen hatte, Beweise hierfür liegen allerdings keine vor. Dobretsberger unterhielt in der Folge enge Kontakte mit den Sowjets und der KPÖ, die selbst als Folge der sich dahinschleppenden Staatsvertragsverhandlungen ab 1950 eine Neutralitätslösung für Österreich propagierte und dies nach der Stalin-Note vom 10. März 1952 intensivierte. ${ }^{71} 1948$ hatte sich erstmals die Neutralitätsparole im Parteiprogramm der DU wiedergefunden. ${ }^{72}$ Finnland galt bekanntermaßen ein erheblich größeres Interesse des Kremls als Österreich, dennoch blieb es dem skandinavischen Land aus vielerlei Gründen erspart, ein sowjetischer Satellitenstaat zu werden. 1948 hatte sich Stalin mit dem Abschluss eines sowjetisch-finnischen Freundschaftsvertrages zufriedengegeben. ${ }^{73}$

Im Frühjahr und Sommer 1952, als die Notenschlacht zwischen West und Ost in vollem Gange war, mehrten sich schließlich Berichte über das Abbröckeln der österreichischen

${ }^{68}$ RGASPI, f. 82, op. 2, d. 1042, S. 101, Berichterstattung Ignat'evs an Malenkov und Vyšinskij, 31. 3. 1952 (Dokument 62). Dobretsberger propagierte in der Folge das Beispiel Finnlands. Am 13.9.1953 unterstrich er in einer Rede auf der Tagung des Präsidiums der Volksopposition den Neutralitätsgedanken, "der am Beispiel F i n n l a n d s den Beweis seiner Notwendigkeit und Durchführbarkeit erbracht hat". Dobretsberger, Neutralität, S. 14. In heutiger Kenntnis der internen sowjetischen Positionierung in der Österreichfrage lesen sich die Forderungen Dobretsbergers wie die eines instrumentalisierten Sprachrohrs des Kremls. Die Rolle Dobretsbergers auf dem Weg Österreichs zur Neutralität, insbesondere seine Vermittlertätigkeit zwischen Kreml und der österreichischen Regierung, gilt es in Zukunft genauer zu untersuchen.

${ }^{69} \mathrm{Am}$ 10.1.1951 wies das Politbüro den sowjetischen Botschafter in Finnland an, einen Grund für ein Gespräch mit Kekkonen zu suchen und „in der Form einer zweiten Frage“ das „Thema der Neutralität“ zu berühren. Der sowjetische Botschafter sollte Kekkonen klar zu verstehen geben, dass sich der Kreml positiv zum „Zusammenschluss der nördlichen Staaten rund um die Idee der Neutralität" verhalte. Der Kreml ging hier direkt auf Kekkonens Initiative ein. Aus der Direktive an den sowjetischen Botschafter: „Sagen Sie, dass Sie die von ihnen [gemeint vermutlich den Finnen] berührte Frage der Neutralität im von Kekkonen dargelegten Plan überdacht haben und dass Sie zu den von ihnen dargelegten Gedanken über den Zusammenschluss der nördlichen Staaten rund um dic Idee der Neutralität zum Zwecke der Festigung des Friedens und der nationalen Unabhängigkeit dieser Länder positiv eingestellt sind. Eine Initiative solcher Art könnte der Verbreitung des Ruheherdes im Norden, über die Kekkonen gesprochen hat, dienlich sein und würde einer Politik der Unterstützung und Festigung des Friedens entsprechen, die im Vertrag über Freundschaft, Zusammenarbeit und gegenseitiger Hilfe zwischen der UdSSR und Finnland [von 1948] zum Ausdruck kommt." RGASPI, f. 17, op. 162, d. 48, S. 12 und 60, Politbüro-Beschluss P 86 (240-op) vom 10.1.1951.

70 RGASPI, f. 82, op. 2, d. 1364, 1365 und 1366.

71 Stourzh, Um Einheit und Freiheit, S. 267.

72 Autengruber, Kleinparteien in Österreich 1945 bis 1966, S. 171.

${ }^{73}$ Büttner, Sowjetisierung oder Selbständigkeit? Zum Vergleich der sowjetischen Finnland- und Österreichpolitik siehe Ruggenthaler, Warum Österreich nicht sowjetisiert werden sollte, S. 81-84. 
Position eines bedingungslosen Unterstützens eines Konfrontationskurses gegenüber der UdSSR. Noch war es zu früh, dass der Kreml auf die von Wien ausgestreckten Fühler eingehen konnte, doch es war der Beginn jenes Prozesses, der schließlich im Herbst 1952, also noch zu Stalins Lebzeiten, zu ersten sowjetisch-österreichischen Gesprächen führte. ${ }^{74}$

Am 19. März 1952 meldete Zorin Molotov, dass dem ÖVP-Vorsitzenden Julius Raab bei seinem Besuch in Washington von den Amerikanern versprochen worden sei, Österreich „bald von den Russen zu erlösen“- eine in dieser Deutlichkeit bisher unbekannte „Zusicherung“ der USA. Raab sei demnach geraten worden, für diesen Zeitpunkt über eine starke Regierung zu verfügen, auf die die USA dann zurückgreifen könne. Zorin brachte gegenüber Molotov seine Meinung zum Ausdruck, „dass im Falle des Zurückweisens des Entwurfes des ,Kurzvertrages“ durch die Sowjetunion die Westmächte gleichzeitig mit der Übergabe der Österreichfrage an die UNO und einer einseitigen Deklaration über die ,Gewährung der Freiheit und Souveränität für Österreich` auftreten könnten, der zufolge der Abzug ihrer Truppen vom Territorium Österreichs den Abzug der sowjetischen Besatzungstruppen bedingt. "75 Dies war freilich lediglich eine theoretische Möglichkeit, das ÖsterreichProblem zu lösen. Außenminister Gruber hatte am 12. Februar 1952 in einer Sitzung des Nationalratsklubs der ÖVP eine solche Variante vollkommen ausgeschlossen. Sie sei „undenkbar" und „dies wäre das Ende Österreichs“. In Wien war man sich bewusst, dass ein Abzug aller Alliierten Truppen einzig und allein mit einer zu erhoffenden weltpolitischen Entspannung möglich wäre. ${ }^{76}$ Die bereits im Januar 1952 vorgenommene Regierungsumbildung in Wien charakterisierte Zorin als Einschlagen eines „harten“ Kurses gegenüber der UdSSR und der KPÖ, als vorbereitende amerikanische Maßnahme zur Einbeziehung Österreichs in die NATO ${ }^{77}$ Der SPÖ sei zur Unterstützung der Maßnahmen für die „Verteidigung Europas gegen die UdSSR und ihre Verbündeten“, wie allen sozialistischen Parteien Europas von der „Sozialistischen Internationale“ im Dezember 1951 in Brüssel empfohlen worden, „unter allen Umständen für die ,Verteidigung“ und die Rüstung betreffenden Posten der Staatshaushalte" zu stimmen. ${ }^{78}$ Die ÖVP sah man auf dem absteigenden Ast. Sie habe 1951 an Einfluss auf die Massen deutlich verloren. Deshalb, so Zorin, habe die ÖVP Anfang 1952 einen außerordentlichen Parteitag abgehalten, der explizit antisowjetischen Charakter getragen habe. ${ }^{79}$ Im Mai 1952 schließlich kritisierte nach Einschätzung des politischen Vertreters Österreichs in Moskau, Norbert Bischoff, die Sowjetunion „erstmals seit Beginn [...] des ,Kalten Krieges“ [...] so offen“ die österreichische Regierung. ${ }^{80}$ Für Raab kam dies freilich einer politischen Unterstützung gleich.

\footnotetext{
${ }^{74}$ Vgl. hierzu Stourzh, Der österreichische Staatsvertrag in den weltpolitischen Entscheidungsprozessen, S. 973f. Im Sommer 1952 hatte die UdSSR nach der Einschätzung Norbert Bischoffs die österreichische Außenpolitik erstmals seit Ausbruch des Kalten Krieges „offen“ kritisiert. RGASPI, f. 82, op. 2, d. 1043, S. 236, Berichterstattung Ignat'evs, 1.7.1952 (Dokument 68).

${ }^{75}$ RGASPI, f. 82, op. 2, d. 1042, S. 82, Berichterstattung Zorins an alle Mitglieder des Politbüros sowie an Vyšinskij und Gromyko, 19.3.1952 (Dokument 61).

${ }^{76}$ Gehler, Kurzvertrag für Österreich, S. 250.

77 RGASPI, f. 82, op. 2, d. 1042, S. 51, Berichterstattung Zorins an Stalin und alle Mitglieder des Politbüros sowie an Vyšinskij und Gromyko, 23.2.1952 (Dokument 55).

${ }^{78}$ RGASPI, f. 82, op. 2, d. 1042, S.78, Berichterstattung Ignat'evs an Malenkov und Zorin, 18. 3. 1952 (Dokument 60).

${ }^{79}$ RGASPI, f. 82, op. 2, d. 1042, S. 61, Berichterstattung Ignat'evs an Stalin und alle Mitglieder des Politbüros, 1.3.1952 (Dokument 56).

${ }^{80}$ RGASPI, f. 82, op. 2, d. 1043, S. 236, Berichterstattung Ignat'evs, 1.7.1952.
} 


\section{Österreich geht zur UNO}

Bundeskanzler Figl verfocht in der Folge die Übergabe der Österreichfrage an die UNO. Moskau war bekannt, dass die österreichische Regierung diesen Schritt nicht ohne Abstimmung mit den Westmächten realisieren würde. ${ }^{81}$ Die spätere Brasilien-Initiative der Einbringung der Österreichfrage auf die Tagesordnung der 7. UN-Vollversammlung ${ }^{82}$ betrachtete man als amerikanisches Unternehmen, ${ }^{83}$ die Franzosen hätten jedoch vorgeschlagen, die UNO-Initiative nicht „wie ein Manöver gegen die UdSSR aussehen“ zu lassen. ${ }^{84}$ Offiziell blieb die UdSSR in der Österreichfrage inaktiv und beobachtete die Entwicklung. Am 7.Juni 1952 berichtete MGB-Chef Ignat'ev Molotov über eine Rede Raabs, in der der ÖVP-Chef proklamiert habe, sich „in keinem Fall fürchten zu dürfen, gegen die Amerikaner aufzutreten [...] und die vorhandenen Sympathien in Österreich für Russland zu berücksichtigen “. ${ }^{5}$ Einige Tage später, am 18. Juni, analysierte Zorin vor Molotov die in letzter Zeit vor sich gegangenen Veränderungen in der österreichischen Regierung infolge des „Kurzvertrages“. ${ }^{86}$ Ignat'ev berichtete am 29.Juli, nach der Meinung Raabs sei der „Kurzvertrag“ „ein billiges Hilfsmittel“ der USA gegen die UdSSR und die Amerikaner wüssten generell nicht, „was sie wollen“. Zudem stünde die Außenpolitik der USA im Zeichen des Wahlkampfes. Bis zu dessen Abschluss sollte die österreichische Regierung den „Anschein erwecken“, als erfülle sie „alle Anweisungen der Amerikaner“. Tatsächlich sollte man alle größeren Maßnahmen auf die Zeit nach den Präsidentenwahlen verschieben. ${ }^{87}$ Mitte August 1952 vermeldete MGBChef Ignat'ev, Acheson habe von der österreichischen Regierung verlangt, die Gründung einer österreichischen Armee zu beschleunigen, um „das Vakuum zwischen Jugoslawien und Westdeutschland aufzufüllen“" ${ }^{88}$ Wien kam dem bekanntermaßen nach. Die Gründung der B-Gendarmerie, ${ }^{89}$ des Vorläufers des österreichischen Bundesheeres, und die Anlegung von Waffenlagern in Österreich durch die amerikanischen und britischen Geheimdienste sind ein Produkt der Ost-West-Konfrontation des frühen Kalten Krieges. ${ }^{90}$

${ }^{81}$ RGASPI, f. 82, op. 2, d. 1042, S. 187, Berichterstattung Ignat'evs an Malenkov, Vyšinskij und Zorin, 29.5.1952 (Dokument 64).

${ }^{82}$ Siehe hierzu Eisterer, Die brasilianische UNO-Initiative 1952; Leidenfrost, Die UNO als Forum für den österreichischen Staatsvertrag?

${ }^{83}$ RGASPI, f. 82, op. 2, d. 1043, S. 299, Berichterstattung Tugarinovs an Stalin und alle Mitglieder des Politbüros sowie an Suslov, Vyšinskij, Grigor'jan, Puškin und Podcerob, 23.8.1952 (Dokument 73). Das State Department gab den Österreichern zu verstehen, dass Brasilien für die Einbringung einer UNOResolution geeignet war. Auch Mexiko, das 1938 im Völkerbund gegen den „Anschluss“ Österreichs protestiert hatte, übernahm die Initiative, brachte schlussendlich jedoch nicht selbst die Österreichfrage vor die UNO. Siehe hierzu Müller, Die versäumte Freundschaft, S. 228-243.

${ }_{84}$ RGASPI, f. 82, op. 2, d. 1043, S. 288, Berichterstattung Ignat'evs an Malenkov und Vyšinskij, 15. 8. 1952 (Dokument 72).

${ }^{85}$ RGASPI, f. 82, op. 2, d. 1043, S. 200, Berichterstattung Ignat'evs an Malenkov und Vyšinskij, 7.6. 1952 (Dokument 66).

${ }^{86}$ RGASPI, f. 82, op. 2, d. 1043, S. 215, Berichterstattung Zorins an Vyšinskij und Puškin, 18.6.1952 (Dokument 67).

${ }^{87}$ RGASPI, f. 82, op. 2, d. 1043, S. 268, Berichterstattung Ignat'evs an Malenkov, Berija, Bulganin und Vyšinskij, 29.7.1952 (Dokument 69).

${ }^{88}$ RGASPI, f. 82, op. 2, d. 1043, S. 286, Berichterstattung Ignat'evs an Stalin und alle Mitglieder des Politbüros und Vyšinskij, 14.8.1952 (Dokument 71).

${ }^{89}$ Siehe hierzu zuletzt Blasi/Schneider/Schmidl (Hrsg.), B-Gendarmerie, Waffenlager und Nachrichtendienste. Der militärische Weg zum Staatsvertrag.

${ }^{90}$ Ebd., insbesondere folgende Beiträge: Blasi/Etschmann, Überlegungen zu den britischen Waffenlagern in Österreich; und Ortner, Die amerikanischen Waffendepots in Österreich. 
Erst am 14. August 1952 lehnte Moskau den „Kurzvertrag“ in einer Note ab, ${ }^{91}$ schlug aber eine Wiederaufnahme der Staatsvertragsverhandlungen auf der Basis des alten Vertragsentwurfes vor. Vier Tage zuvor hatte Ignat'ev Molotov ausführlich Bericht über den Telegrammverkehr zwischen dem Wiener Außenamt und dem politischen Vertreter in Moskau des Jahres 1952 erstattet. Bischoff hatte demzufolge Außenminister Gruber dargelegt, die Sowjetunion plane keinen Angriffskrieg auf Europa bzw. keinen Dritten Weltkrieg. ${ }^{92}$ Aus Geheimdienstinformationen vernahm der Kreml, dass Washington nicht zu weiteren Verhandlungen über Österreich auf der Basis des alten Staatsvertragsentwurfes bereit sein werde und auf der Übergabe der Österreichfrage an die UNO bestand..$^{93}$ Am 24. September lehnte Moskau den „Kurzvertrag“ ein zweites Mal ab. ${ }^{94}$ Nun war die Gesprächsbereitschaft des Kremls wieder da, zumindest pro forma. Im Herbst 1952 konnte die UdSSR nunmehr wieder leichten Herzens Gesprächsbereitschaft in der Österreichfrage bekunden - sofern der „Kurzvertrag“ kein Thema mehr sein würde; denn die Teilung Deutschlands war unumkehrbar geworden und ein sozialistischer Staat in Ostdeutschland gefestigt.

Am 20. Dezember nahm die UN-Generalversammlung eine Resolution mit der Forderung des raschen Abschlusses des österreichischen Staatsvertrages an. ${ }^{95}$ Die sowjetische Delegation hatte die Direktive, sich an der Abstimmung nicht zu beteiligen. ${ }^{96}$ Sie hatte zuvor auch nicht verhindern können, dass die Österreich-Frage auf die Tagesordnung der UNOVollversammlung kam. ${ }^{97}$

Die Teilung Deutschlands ebnete schließlich aus der Sicht des Kremls den Weg für eine „Neutralisierung“ Österreichs. Neutralität für Österreich war von größerem Nutzen als eine

${ }^{91}$ Die entsprechenden Antworten wurden von Vyšinskij im Juli vorbereitet und Molotov zweimal zur Korrektur vorgelegt, ehe sie Stalin vorgelegt wurden. RGASPI, f. 82, op. 2, d. 1115, S. 113-119, Vyšinskij an Molotov mit der Bitte um Anweisungen, 31.7.1952; ebd., S. 120-127, Vyšinskij an Molotov mit der Bitte um Anweisungen, 5. 8.1952. Am 14.8.1952 beschloss das Politbüro die Note. RGASPI, f. 17, op. 163, d. 1627, S. 140-146, Politbüro-Beschluss P 89 (74) vom 14.8.1952.

${ }_{92}$ RGASPI, f. 82, op. 2, d. 1043, S. 282, Berichterstattung Ignat'evs, 10.8. 1952 (Dokument 70). Bischoff sah sich im österreichischen Außenministerium dem Vorwurf ausgesetzt, er habe in seiner Zeit als politischer Vertreter (und später Botschafter) in der UdSSR den Realitätssinn verloren. Seine politischen Berichte sind durchwegs gekennzeichnet von Sympathie gegenüber Land und Volk sowie den „Errungenschaften“ der Sowjetunion. Die österreichische Regierung vertraute dennoch stets Bischoff. Den Erinnerungen seines damaligen Sekretärs zufolge, Herbert Grubmayr, und des persönlichen Sekretärs des österreichischen Bundeskanzlers Raab, Ludwig Steiner, war Bischoff davon überzeugt, jedes Wort bzw. jede geschriebene Zeile in der österreichischen Botschaft werde abgehört und mitgeschnitten. Im internsten Kreis soll sich Bischoff des Öfteren antisowjetisch geäußert haben. An dieser Stelle danke ich Herrn Botschafter Dr. Ludwig Steiner und Herrn Botschafter Dr. Herbert Grubmayr für diese Hinweise und viele interessante Gespräche. Ein Smerš-Bericht vor der Entsendung Bischoffs nach Moskau bestätigt eine antisowjetische Einstellung Bischoffs vor seinem Amtsantritt in Moskau 1946. AVP RF, f. 06, op. 8, p. 22, d. 305, S. 39f. Siehe auch Grubmayr, Norbert Bischoff, Beschaffer des Staatsvertrages und/oder „unguided missile“ am österreichischen Polithimmel?, S. 376-379.

93 RGASPI, f. 82, op. 2, d. 1043, S.314, Berichterstattung Rumjancevs, 2.9.1952 (Dokument 74).

94 RGASPI, f. 17, op. 3, d. 1096, S. 151-153, Politbüro-Beschluss P 89 (316) des ZK der VKP(b) vom 27.9.1952. Entwurf der 1. Note an Stalin in RGASPI, f. 82, op. 2, d. 1115, S.128-135, Entwurf der 2. Note in ebd., S.152-158. Zur Ablehnung des Kurzvertrages durch die UdSSR siehe Stourzh, Um Einheit und Freiheit, S. 187.

${ }_{95}$ Eisterer, Die brasilianische UNO-Initiative 1952, S. 354.

96 RGASPI, f. 17, op. 162, d. 48, S. 149 und 154-175, hier S. 167f., Politbüro-Beschluss P 86 (319-op) vom 29.9.1952, Anweisungen für die sowjetische Delegation der VII. UNO-Vollversammlung. Siehe auch RGASPI, f. 82, op. 2, d. 1083, S. 114, 133 und 154, Dircktivenentwürfe Vyšinskijs an Molotov, September 1952.

97 Eisterer, Die brasilianische UNO-Initiative 1952, S. 351-354. 
Teilung des kleinen Landes, die am Ende wiederum zu einer Stärkung Westdeutschlands geführt hätte. Westösterreich wäre wohl allein kaum lebensfähig gewesen. Der Kreml hatte seine Ziele in Mitteleuropa erreicht: Deutschland würde auf lange Zeit nicht wieder erstarken: die unwiderrufliche Teilung des Landes und die militärische „Neutralisierung“ Österreichs waren hierzu die wichtigsten Mittel. Ob es sich hierbei freilich um ein Mindest- oder gar Maximalziel der sowjetischen Außenpolitik der Nachkriegszeit handelte, ist eine andere Frage.

Alles in allem war der „Kurzvertrag“, der eindeutig gegen die Interessen der UdSSR gerichtet war (dies hielt auch Molotov in seinen ersten Korrekturen auf dem von Vyšinskij vorgelegten Papier fest), ${ }^{98}$ ein für die Sowjets weiteres, geradezu ideales diplomatisches Mittel zum Zweck, nicht in Staatsvertragsverhandlungen eintreten zu müssen. Der Westen wollte mit der Österreich-Frage die sowjetischen Absichten in der Deutschland-Frage abtesten. Vyšinskij hatte im Zuge der „Notenschlacht“ Stalin darauf hingewiesen, dass ja auch der Westen in erster Linie an der deutschen Frage interessiert sei. Eine Lösung des Österreichproblems hätte freilich nicht nur die Gesprächsbereitschaft Stalins, die ja in der deutschen Frage in den vielen Noten 1952 scheinbar zutage getreten war, bekräftigt, sondern auch gezeigt, dass sie zu konkreten Ergebnissen führen könnte. Stalin konnte 1952 nicht über Österreich verhandeln lassen und folglich eine mögliche „Modellfall“-Lösung für Deutschland schaffen. Österreich war aus der Sicht des Kremls zweifacher Konsolidierungsfaktor des Ostblocks: in erster Linie als Legitimation für die sowjetische Truppenpräsenz in Ungarn und Rumänien, darüber hinaus hätten sich in Deutschland unweigerlich Stimmen nach einer ähnlichen Lösung erhoben und letztlich die Existenz der DDR ernsthaft gefährdet.

Deutschland wurde geteilt, Österreich nicht. Ostdeutschland wurde sowjetisiert, in der sowjetischen Besatzungszone in Ostösterreich wurden nie Sowjetisierungsmaßnahmen ergriffen. Dennoch: sowohl die sowjetische Deutschland- als auch die Österreichpolitik unterlagen denselben Prämissen. Hier die forcierte Teilung und Sowjetisierung, dort keine Teilung und keine Sowjetisierung - beiden Konstanten liegen sowjetische sicherheitspolitische Interessen zugrunde. In Ostdeutschland war der Aufbau des Sozialismus in erster Linie Mittel zum Zweck. Sicherheitspolitische Ziele deckten sich hier freilich zugleich mit ideologischen, sie gingen Hand in Hand. In Österreich konnte nicht nur, sondern es musste auf die ideologische Komponente verzichtet werden, um prioritäre Ziele umzusetzen. ${ }^{99}$ Stalin hatte sich einer ausgeklügelten Taktik bedient. Und seine Nachfolger führten seine Außenpolitik fort. Auch nach dem Abschluss des Staatsvertrages mit Österreich am 15. Mai 1955 sollte Österreich kein Modellfall für Deutschland werden. ${ }^{100}$ Außenminister Molotov, der direkt aus Warschau, wo der Warschauer Pakt unterzeichnet worden war, nach Wien an-

98 „Kurzvertrag“ - Verletzung der Rechte der UdSSR (nach dem Potsdamer Abkommen). "RGASPI, f. 82, op. 2, d. 1115, S.114. Entwurf einer Antwortnote zum „Kurzvertrag“ an die Westmächte von Vyšinskij mit handschriftlichen Anweisungen Molotovs, 31. 7. 1952.

99 Siehe hierzu bereits meine Ausführungen, allerdings nur auf der Basis der Österreich-Akten des Molotov-Bestandes in Ruggenthaler, Warum Österreich nicht sowjetisiert wurde, S. 700-705.

100 Siehe hierzu die nach wie vor gültigen Analysen und Rückschlüsse bei Thoß, Modellfall Österreich? Die sowjetische Besatzung Österreichs war allerdings keine Belastung für Stalin. Vgl. Naimark, Stalin and Europe in the Postwar Period, S.56. Unter gewissen Umständen wäre, wie oben ausgeführt, ein Abschluss des österreichischen Staatsvertrages auch unter Stalin möglich gewesen. Zur Neutralisierung Österreichs bedurfte es nicht des Todes Stalins, sondern wohl der Konsolidierung der DDR. Zwischen 1949 und 1952 hätte Stalin zu einer solchen seine Zustimmung allordings nicht gegeben. Vgl. ebd. 
reiste, hatte sich an die Weisung des Präsidiums des ZK zu halten, in Wien mit den Westmächten nicht über die deutsche Frage zu sprechen. ${ }^{101}$ Ein verlockendes Angebot des Kremls an die Adresse der Westdeutschen blieb diesmal und in der Folge aus, auch wenn die sowjetische Presse Andeutungen machte, „dass Deutschland aus den Moskauer Verhandlungen mit Österreich [im April 1955] nützliche Schlüsse ziehen kann“. ${ }^{102}$

101 Stourzh, Der österreichische Staatsvertrag in den weltpolitischen Entscheidungsprozessen, S. 991. 102 Radio Moskau am 4.5. 1955. Zitiert nach Thoß, Modellfall Österreich?, S. 134. 


\section{Dokumente}

\section{Dokument 51}

AVP RF, f. 66 , op. 29 , p. 49 , d. 11, S. 25-27, 28.2.1950

\section{An Genossen A. Ja. Vyšinskij}

Schlussfolgerung zum Vorschlag der Gen. Cinev und Koptelov über die Einfügung eines neuen, zusätzlichen Artikels in den Entwurf des Österreichvertrages ${ }^{103}$

Die Gen. Ginev und Koptelov schlagen vor, in den Entwurf des Österreichvertrages einen neuen Artikel einzufügen, der Österreich verpflichtet, in keine militär-politischen Blöcke einzutreten, die gegen eine der Besatzungsmächte Österreichs gerichtet sind.

Die Einbringung eines solchen Vorschlags zur Erörterung durch die Sonderbevollmächtigten halte ich aus folgenden Gründen für nicht zielführend:

1. In keinem der fünf Verträge mit Italien, Finnland, Bulgarien, Rumänien und Ungarn gibt es solche Artikel. Deshalb würde die Einfügung eines entsprechenden Artikels in den Entwurf des Vertrages mit Österreich in gewissem Maße eine diskriminierende Haltung gegenüber Österreich bedeuten.

2. Unser Vorschlag über die Einfügung eines neuen Artikels in den Vertragsentwurf würde als Versuch der Begrenzung der Souveränität Österreichs ausgelegt werden.

3. Ein solcher Vorschlag kann von den Vertretern des anglo-amerikanischen Blocks als Bekundung großer Unruhe sowjetischer Vertreter vor dem Nordatlantikpakt ausgelegt werden.

4. Die Einbringung der Erörterung eines neuen Artikels unsererseits nach einigen Jahren der Erörterung des Vertragsentwurfs würde von den Anglo-Amerikanern und den Österreichern zur antisowjetischen Propaganda benutzt werden und uns dem Verdacht aussetzen, mittels ausgeklügelter Versuche, die Vorbereitung des Entwurfs des Österreichvertrages zu verzögern.

5. Eines der Hauptziele des Österreichvertrages ist die Nichtzulassung eines Bündnisses Österreichs mit Deutschland. Dies ist mit Artikel 4 des Vertragsentwurfes vorgesehen, der „ein politisches oder wirtschaftliches Bündnis zwischen Österreich und Deutschland" in welcher Form auch immer verbietet.

Die 3. Europäische Abteilung schlägt vor, dass man in unserer weiteren Vorgehensweise in der Frage der Vorbereitung des Entwurfs des Österreichvertrages von folgendem ausgehen könnte:

1. Gen. Zarubin besteht weiterhin auf der Erörterung der Artikel, über die noch keine Übereinkunft erzielt wurde /16, 27, 35-bis, 42 und 48/ und auf der Annahme unserer Vorschläge zu allen diesen Artikeln.

Im Falle der Erzielung einer Übereinkunft zu den genannten Artikeln kann Gen. Zarubin sein Einverständnis zur Arbeit des Redaktionskollegiums geben, die eine gewisse Zeit in Anspruch nimmt.

${ }^{103}$ Am linken Rand der handschriftliche Vermerk: „Zu den Akten. M[ichail]. G[ribanov]. 7.III.50“. 
2. In Wien könnte man Verhandlungen mit der österreichischen Regierung zur Regelung der gegenseitigen Ansprüche beginnen, die einige Monate in Anspruch nehmen werden /Vereinbarung der Nomenklatur der Waren, die von uns an Österreich geliefert werden, der Preise, der Bedingungen der Warenlieferungen usw./

3. Es wäre zielführend, dass unsere Vertreter im Alliierten Rat wieder die Frage der Notwendigkeit eines Berichtes der österreichischen Regierung über die Durchführung der Entmilitarisierung und Entnazifizierung zur Erörterung bringen (diese Frage brachten sie auf Anweisung des Außenministeriums der UdSSR am 9.XII.49 ein).

Im Falle einer neuerlichen Ablehnung dieses Vorschlags von uns durch die Vertreter der Westmächte könnten wir diese Tatsache zur weiteren Entlarvung der aggressiven Politik der Westmächte in Bezug auf Österreich benutzen.

Wenn dieser Vorschlag auf der Sitzung des Alliierten Rates abgelehnt wird, könnte Gen. Zarubin den Sonderbeauftragten vorschlagen, vom Alliierten Rat in Österreich mit entsprechender Begründung einen Bericht über die Erfüllung des Programms der Entmilitarisierung und der Entnazifizierung Österreichs zu erbitten.

Da es in Österreich tatsächlich zu einem Aufleben der Tätigkeiten verschiedener neofaschistischer Organisationen kommt und das militärisch-industrielle Potential erhalten und sogar weiterentwickelt wird, können wir durch die Frage nach den Ergebnissen der Entmilitarisierung und Entnazifizierung die Grundlage für eine zukünftige Erklärung darüber schaffen, dass die Verletzung der vierseitigen Beschlüsse über die Entmilitarisierung und Entnazifizierung durch die österreichische Regierung ein neues ernsthaftes Hindernis zur Beschleunigung der Vorbereitung des Entwurfs des Österreichvertrages ist.

M. Gribanov /M. Gribanov/

„28.“ Februar 1950

\section{Dokument 52}

RGASPI, f. 82, op. 2, d. 1041, S. 153, 1.8.1951

Zorin: Trägt vor, dass aus Wien Hinweise über die Absicht der Regierung der USA, die Verhandlungen in der Frage über den österreichischen Vertrag wieder aufzunehmen, eingetroffen sind. Darüber wird in einem geheimen Bericht gesprochen, den Gruber am 20.Juli d. J. von seinem politischen Vertreter in den USA erhalten hat. In diesem Bericht heißt es, dass zum Zwecke der Beschleunigung des Abschlusses des Vertrages die Regierung der USA bereit sei, der österreichischen Regierung finanzielle Hilfe zur Deckung der von der Sowjetunion gegenüber Österreich geltend gemachten Schulden zu erweisen.

(Erging an Gen. Gromyko).

\section{Dokument 53}

RGASPI, f. 82, op. 2, d. 1042, S. 7, 9. 1.1952

Ignat'ev: Trägt den Inhalt des Telegramms vor, das vom Apparat des französischen Hochkommissars in Österreich an das Außenministerium Frankreichs am 15. Dezember 1951 gerichtet wurde. In dem Telegramm wird mitgeteilt, dass der Vertreter der USA bei der 
Konferenz der Sonderbeauftragten für den österreichischen Staatsvertrag, Reber, während seines Wien-Aufenthaltes im Dezember 1951 den Hochkommissaren der Westmächte in Österreich erklärt hat, dass er beabsichtigte, die Konferenz der stellvertretenden Minister der vier Mächte lediglich auszunutzen, um im Falle ihres Scheiterns eine Möglichkeit zu einem Appell an die UNO in dieser Frage zu haben. Während der Verhandlungen Rebers mit den drei Hochkommissaren wurde Übereinstimmung darüber erzielt, ,trotz der Unvollkommenheit des österreichischen Vertrages in seiner jetzigen Form den Vertrag besser zu unterschreiben, als die gegenwärtig existierende Lage aufrechtzuerhalten“. Im Telegramm wird aufgezeigt, dass Reber selbst dazu geneigt ist, bezüglich der Annahme der „sowjetischen Variante“ der Artikel, über die keine Übereinkunft erzielt wurde, „sehr weit“ zu gehen, die Regierung der USA aber ihre Position in dieser Frage noch nicht endgültig festgelegt habe. Zudem wird in dem Telegramm vermerkt, dass die Regierung der USA beabsichtigt, jegliche sowjetische Vorschläge zurückzuweisen, deren Annahme „neue Zugeständnisse" seitens der USA bedeuten können.

Erging an Gen. Gromyko.

\section{Dokument 54}

RGASPI, f. 17, op. 162, d. 48, S. 13 und 63f., 17.1. 1952

[Punkt] 283. - Über die Anweisungen an Gen. Zarubin bezüglich des Außenministeriums Englands zur Frage über die Einberufung einer Konferenz der Sonderbeauftragten für die Vorbereitung des Vertrages mit Österreich.

Den Entwurf der Anweisungen an Gen. Zarubin zu bestätigen (liegt bei). Den Brief Gen. Zarubins am 18., 19. Januar an das Außenministerium Englands zu schicken.

Auszüge ergingen an: die Gen. Molotov, Gromyko.

Zu Pkt. 283(op) des Pr[otokolls] Nr. 85 des P[olit]b[üros]

$\underline{\text { Str. geheim }}$

Vordringlich

London

An Zarubin

Nr. 1217-1219. Erstens. Schicken Sie Passant folgendes Schreiben.

„Ich bestätige den Erhalt Ihres Schreibens vom 28. Dezember 1951 zur Frage der Einberufung einer Konferenz der Sonderbeauftragten zur Vorbereitung des Staatsvertrages mit Österreich in London am 21.Januar und halte es für nötig, folgendes mitzuteilen.

Wie bekannt ist, brachte die sowjetische Delegation in der letzten Sitzung der Sonderbeauftragten den Vorschlag ein, in allen vier Zonen Österreichs eine Überprüfung der Umsetzung der Beschlüsse der vier Mächte über die Entmilitarisierung und Entnazifizierung durch die österreichische Regierung durchzuführen, damit der Alliierte Rat einen Bericht über die Ergebnisse dieser Überprüfung vorlegen kann. Eine solche Überprüfung wurde nunmehr noch notwendiger als früher.

Die sowjetische Delegation wies in den Sitzungen der Sonderbeauftragten mehrmals daraufhin, dass unter den gegebenen Umständen die Frage des Vertrages mit Österreich 
nicht unabhängig von der Frage der Umsetzung der Verpflichtungen in Bezug auf den Friedensvertrag mit Italien durch die Regierungen Englands, der USA und Frankreichs geprüft werden darf. Dies betrifft die Schaffung eines Freien Territoriums Triest [Freistaat Triest], was bis jetzt wegen der gegensätzlichen Handlungen seitens der USA, Englands und Frankreichs noch nicht geschehen ist, Triest wurde hingegen in eine anglo-amerikanische Militärbasis umgewandelt. Welche Garantie gibt es unter solchen Umständen für die Umsetzung des vorzubereitenden Vertrages mit Österreich?

Im Zusammenhang mit dem Vorschlag über die Einberufung einer neuen Konferenz der Sonderbeauftragten bittet die Sowjetdelegation, die Zustimmung der Regierung Großbritanniens, und ebenso der Regierungen der USA und Frankreichs, mitzuteilen, auf dieser Konferenz der Sonderbeauftragten die oben genannten Vorschläge der sowjetischen Delegation über die Durchführung einer vierseitigen Überprüfung in Österreich und über die Umsetzung des Beschlusses über das Freie Territorium Triest zu prüfen.

Kopien des vorliegenden Schreibens wurden von mir auch den Vertretern der USA und Frankreichs auf der Konferenz der Sonderbeauftragten zur Vorbereitung des Entwurfes des österreichischen Vertrages übersandt."

Zweitens. Zu Ihrer Kenntnisnahme teilen wir mit, dass unsere Antwort auf den Vorschlag über die Einberufung der Konferenz der Sonderbeauftragten für den 21.Januar darauf abzielt, den Plan der drei Mächte, eine Konferenz zum Österreichvertrag vor Beendigung der Session der Generalversammlung durchzuführen, zu stören und damit den drei Mächten die Möglichkeit zu nehmen, bei Nichterlangung einer Übereinkunft die Frage des Österreichvertrages vor die Versammlung zu bringen, wie es bereits in der Presse verlautbart wurde.

Das Aufwerfen der Fragen durch uns im Schreiben an Passant über die Durchführung einer vierseitigen Überprüfung in Österreich und über Triest nötigt die drei Mächte, noch vor der Konferenz ihre Meinung zu diesen unseren Vorschlägen von politischer Bedeutung kundzutun, ohne ihnen dabei die Möglichkeit zu geben, die Angelegenheit des Österreichvertrages an Divergenzen zu einzelnen, zweitrangigen Punkten bezüglich dieses Vertrages festzumachen. Damit stärkt sich auch politisch unsere Position auf der Konferenz selbst.

Bestätigen Sie den Erhalt.

Telegraphieren Sie die Durchführung.

A. Gromyko

\section{Dokument 55}

RGASPI, f. 82, op. 2, d. 1042, S. 51, 23.2.1952

Zorin: Legt einen Bericht „Über die Lage im Lager der österreichischen Reaktion im Zusammenhang mit der Einbeziehung Österreichs in den aggressiven Block" vor, in dem es heißt, dass die Amerikaner einen Kurs zum Zusammenschluss der Kräfte der österreichischen Reaktion eingeschlagen haben, was seinen Ausdruck vor allem in den Maßnahmen zur Schaffung einer Regierung einer „starken Hand“ in Österreich findet. Als Ergebnis der Umbesetzung des Kabinetts Figls im Januar d. J. wurden aus der Regierung einige, den Amerikanern nicht genehme Minister entfernt und an ihrer Stelle wurden unmittelbare amerikanische Schützlinge aus der Volkspartei ernannt. Die neue Regierung beabsich- 
tigt einen „harten“ Kurs in Bezug auf die UdSSR und die österreichischen demokratischen Kräfte zu führen und Maßnahmen zur Militarisierung Österreichs zu beschleunigen. Der Kurs auf den Zusammenschluss der österreichischen Reaktion findet seinen Ausdruck auch in der Vorbereitung einer neuen Massenpartei neofaschistischer Ausrichtung. Die Notwendigkeit der Gründung einer solchen Partei ergab sich als Folge des Umstandes, dass der „Verband der Unabhängigen“, der früher das grundlegende legale neofaschistische Zentrum war, sich in letzter Zeit im Zustand einer tiefen Krise befand und seine Autorität in den Kreisen der ehemaligen Nationalsozialisten verlor. Die bedingungslose Unterstützung des amerikanischen Kurses durch die österreichischen Regierungsparteien schwächt sie zusehends in den Augen der Massen und kann zu einem Austritt gewöhnlicher Mitglieder und Anhänger aus diesen Parteien führen. Diese Umstände schaffen günstige Bedingungen zur Festigung des demokratischen Lagers und zur Erweiterung seines Einflusses in den Massen.

Erging an Gen. Stalin und die and. Genossen des Achterkollegiums, ebenso an Gen. Vyšinskij, Gromyko.

\section{Dokument 56}

RGASPI, f. 82, op. 2, d. 1042, S. 61, 1.3.1952

Ignat'ev: Teilt mit, dass im Jahr 1951 der Einfluss der österreichischen Volkspartei auf die Massen deutlich gesunken ist. Die deswegen in Besorgnis versetzte Führung der ÖVP hielt Anfang 1952 einen außerordentlichen Parteitag ab, auf dem eine Reihe demagogischer Beschlüsse angenommen wurden, die dazu auffordern, den Einfluss der Partei unter den Massen in erster Linie unter ehemaligen Nazis „zu festigen“. Der Parteitag trug einen klar ausgedrückten antisowjetischen Charakter. Die speziell durchgeführte Wahl der Delegierten des Parteitages (die Delegierten des Parteitages werden in der Regel nicht gewählt, sondern ernannt) schloss die Möglichkeit des Aufkommens ernsthafter Unstimmigkeiten auf dem Parteitag aus. Die von der Parteiführung getroffenen Maßnahmen festigten die Positionen der führenden, offen proamerikanischen, von Raab geleiteten Parteispitze.

Erging an Gen. Stalin und die and. Genossen des Achterkollegiums.

\section{Dokument 57}

RGASPI, f. 82, op. 2, d. 1042, S.68, 11.3. 1952

Ignat'ev: Stellt den Text des vom Apparat des französischen Hochkommissars in Österreich im Juli 1951 erstellten Berichtes „Über die Politik der UdSSR in Österreich“ vor. Was die Frage des Österreichvertrages betrifft, bringen die Verfasser des Berichtes die Vermutung zum Ausdruck, dass die UdSSR diesen Vertrag unterzeichnen würde, wenn sie überzeugt wäre, dass sich Österreich im Weiteren nicht dem Nordatlantikbündnis anschließt. Diese Position der UdSSR beruht angeblich nicht nur auf wirtschaftlichen, sondern auch auf politischen Vorteilen, die im Falle der Unterzeichnung des Vertrages mit Österreich eintreten würden. Nach der Meinung der Verfasser des Berichtes wäre ein Abzug der Truppen der Westmächte der allergrößte Vorteil für die UdSSR. Die UdSSR verhindert mit Hilfe des vierseitigen Kontrollsystems den Beitritt Österreichs zum Nordatlantikbündnis. Die Verfasser des Berichtes ziehen den Schluss, dass eine mögliche Tei- 
lung Österreichs in der gegenwärtigen internationalen Situation ebenso nicht den Interessen der sowjetischen Außenpolitik entspräche, wo sie doch den politischen und wirtschaftlichen Vorteilen, die die UdSSR schon gegenwärtig in Österreich hat, nichts hinzufügen könnte.

\section{Dokument 58}

\section{„Kurzvertrag“}

Quelle: Stourzh, Geschichte des Staatsvertrages, S. 220-222., 13.3. 1952

\section{Vorschlag der Regierungen der USA, Großbritanniens und Frankreichs für einen abgekürzten Staatsvertrag für Österreich}

\section{Präambel}

Die Union der Sozialistischen Sowjetrepubliken, die Vereinigten Staaten von Amerika, das Vereinigte Königreich Großbritannien und Nordirland und Frankreich, in der Folge die Alliierten und Assoziierten Mächte genannt, einerseits und Österreich andererseits;

Im Hinblick darauf, dass Hitler-Deutschland am 13. März 1938 Österreich mit Gewalt annektierte und sein Gebiet dem Deutschen Reich einverleibte;

Im Hinblick darauf, dass in der Moskauer Erklärung vom 1. November 1943 die Regierungen der Union der Sozialistischen Sowjetrepubliken, des Vereinigten Königreichs und der Vereinigten Staaten von Amerika erklärten, dass sie die Annexion Österreichs durch Deutschland am 13. März 1938 als null und nichtig betrachten, und ihrem Wunsche Ausdruck gaben, Österreich als einen freien und unabhängigen Staat wiederhergestellt zu sehen, und dass das Französische Komitee der Nationalen Befreiung am 16. November 1943 eine ähnliche Erklärung abgab;

Im Hinblick darauf, dass als Ergebnis der alliierten Siege Österreich von der Gewaltherrschaft Hitler-Deutschlands befreit wurde;

Im Hinblick darauf, dass die Alliierten und Assoziierten Mächte und Österreich unter Berücksichtigung der Bedeutung der Anstrengungen, die das österreichische Volk zur Wiederherstellung und zum demokratischen Wiederaufbau seines Landes selbst machte und weiter zu machen haben wird, den Wunsch hegen, einen Vertrag abzuschließen, der Österreich als einen freien, unabhängigen und demokratischen Staat wiederherstellt, wodurch sie zur Wiederaufrichtung des Friedens in Europa beitragen;

Im Hinblick darauf, dass die Alliierten und Assoziierten Mächte und Österreich zu diesem Zwecke den Wunsch hegen, den vorliegenden Vertrag abzuschließen, um als Grundlage freundschaftlicher Beziehungen zwischen ihnen zu dienen und um damit die Alliierten und Assoziierten Mächte in die Lage zu versetzen, die Bewerbung Österreichs um Zulassung zur Organisation der Vereinten Nationen zu unterstützen;

Haben daher die unterfertigten Bevollmächtigten ernannt, welche nach Vorweisung ihrer Vollmachten, die in guter und gehöriger Form befunden wurden, über die nachstehenden Bestimmungen übereingekommen sind:

\section{Artikel 1.}

Wiederherstellung Österreichs als freier und unabhängiger Staat 
Die Alliierten und Assoziierten Mächte anerkennen, dass Österreich als ein souveräner, unabhängiger und demokratischer Staat wiederhergestellt ist.

Artikel 2.

Bewahrung der Unabhängigkeit Österreichs

1. Die Alliierten und Assoziierten Mächte erklären, dass sie die Unabhängigkeit und territoriale Unversehrtheit Österreichs, wie sie gemäß dem vorliegenden Vertrag festgelegt sind, achten werden.

2. Die Alliierten und Assoziierten Mächte erklären, dass eine politische oder wirtschaftliche Vereinigung zwischen Österreich und Deutschland (Anschluss) verboten ist. Österreich anerkennt voll und ganz seine Verantwortlichkeiten auf diesem Gebiet.

Artikel 3.

Die Grenzen Österreichs sind jene, die am 1. Jänner 1938 bestanden haben.

Artikel 4.

Zurückziehung der alliierten Streitkräfte

1. Das Übereinkommen über den Kontrollapparat in Österreich vom 28. Juni 1946 verliert mit dem Inkrafttreten des vorliegenden Vertrages seine Wirksamkeit.

2. Mit dem Inkrafttreten des vorliegenden Vertrages hört die gemäß $\S 4$ des Abkommens über Besatzungszonen in Österreich und die Verwaltung der Stadt Wien vom 9.Juli 1945 errichtete interalliierte Regierungsbehörde (Komendatura) auf, irgendwelche Funktionen hinsichtlich der Verwaltung der Stadt Wien auszuüben. Das Übereinkommen über die Besatzungszonen in Österreich tritt mit der Beendigung der Räumung Österreichs durch die Streitkräfte der Alliierten und Assoziierten Mächte und jedenfalls mit dem Ablauf von 90 Tagen, angefangen vom Inkrafttreten des vorliegenden Vertrages, außer Kraft.

3. Die Streitkräfte der Alliierten und Assoziierten Mächte und die Mitglieder der Alliierten Kommission für Österreich werden so bald wie möglich und jedenfalls innerhalb von 90 Tagen, angefangen vom Inkrafttreten des vorliegenden Vertrages, aus Österreich zurückgezogen.

4. Die österreichische Regierung wird den Streitkräften der Alliierten und Assoziierten Mächte und den Mitgliedern der Alliierten Kommission für Österreich bis zu ihrer Zurückziehung aus Österreich alle Rechte, Immunitäten und Erleichterungen gewähren, die ihnen unmittelbar vor dem Inkrafttreten des vorliegenden Vertrages zustanden.

5. Die Alliierten und Assoziierten Mächte verpflichten sich, der österreichischen Regierung innerhalb des festgesetzten Zeitraumes von 90 Tagen zurückzustellen:

a) alle Zahlungsmittel, die den Alliierten und Assoziierten Mächten für Okkupationszwecke kostenlos zur Verfügung gestellt worden und im Zeitpunkt der Beendigung der Zurückziehung unverausgabt geblieben sind;

b) alles österreichische Eigentum, das von alliierten Streitkräften oder von der Alliierten Kommission requiriert wurde und sich noch in deren Besitz befindet.

Artikel 5.

Reparationen

Von Österreich werden keine Reparationen verlangt, die sich aus dem Bestehen eines Kriegszustandes in Europa nach dem 1. September 1939 ergeben. 
Artikel 6.

Kriegsbeute - Deutsches Eigentum in Österreich

Jede der Alliierten und Assoziierten Mächte soll innerhalb des in Artikel 4 festgesetzten Zeitraumes von 90 Tagen alles Eigentum - unbewegliches und bewegliches jeder Art -, das sich als deutsches Eigentum oder Kriegsbeute in Österreich in ihrem Besitz befindet oder von ihr beansprucht wird, an Österreich zurückgeben.

\section{Artikel 7.}

\section{Beitrittsklausel}

1. Jedes Mitglied der Vereinten Nationen, das sich mit Deutschland im Kriegszustand befunden hat, den Status einer Vereinten Nation am 8. Mai 1945 besaß und nicht Signatar des vorliegenden Vertrages ist, kann dem Vertrag beitreten und ist nach Beitritt für die Zwecke des Vertrages als Assoziierte Macht anzusehen.

2. Die Beitrittsurkunden werden bei der Regierung der Union der Sozialistischen Sowjetrepubliken hinterlegt werden und treten mit der Hinterlegung in Kraft.

\section{Artikel 8.}

\section{Ratifizierung}

Der vorliegende Vertrag, dessen russischer, englischer und französischer Text authentisch ist, soll ratifiziert werden. Er tritt unmittelbar nach Hinterlegung der Ratifikationsurkunden durch die Union der Sozialistischen Sowjetrepubliken, durch das Vereinte Königreich Großbritannien und Nordirland, durch die Vereinigten Staaten von Amerika und durch Frankreich einerseits und durch Österreich andererseits in Kraft. Die Ratifikationsurkunden werden in möglichst kurzer Zeit bei der Regierung der Union der Sozialistischen Sowjetrepubliken hinterlegt werden.

Der Vertrag wird bezüglich jeder Alliierten oder Assoziierten Macht, die gemäß Artikel 7 dem Vertrage beitritt und deren Ratifikationsurkunde hienach hinterlegt wird, am Tag der Hinterlegung in Kraft treten.

Der vorliegende Vertrag wird in den Archiven der Regierung der Union der Sozialistischen Sowjetrepubliken hinterlegt werden, die jedem der Signatarstaaten beglaubigte Abschriften übermitteln wird.

\section{Dokument 59}

RGASPI, f. 82, op. 2, d. 1042, S. 78, 18.3.1952

Ignat'ev: Teilt mit, dass entsprechend einer aus den Führungskreisen des französischen Außenministeriums erhaltenen Information auf der Konferenz der Außenminister der USA, Englands und Frankreichs zur Frage über den österreichischen Staatsvertrag der Beschluss gefasst wurde, den ehemaligen Vertragsentwurf lediglich als einen Expertenentwurf zu werten, der die Regierungen der Westmächte zu nichts verpflichtet. Gemäß denselben Angaben unterschied sich während dieser Verhandlungen die Position Frankreichs im Zusammenhang mit dem Entwurf des „Kurzvertrages“ von den Positionen der USA und Englands. Die Amerikaner meinten, dass die sowjetische Regierung vor die Alternative gestellt werden müsse, den Entwurf des „Kurzvertrags“ in der Form, in der er von den Westmächten entworfen wurde, anzunehmen oder abzulehnen. Die Franzosen hingegen hielten es für notwendig, der UdSSR „die Tür offen“ zu halten, um notfalls zum ehemaligen Entwurf zu- 
rückkehren zu können. Ungeachtet der Einwände der Amerikaner und Engländer bestanden die Franzosen darauf, im Text des „Kurzvertrages“ einen Artikel bezüglich des Verbotes eines neuen „Anschlusses“ einzubauen.

Erging an Gen. Stalin und die and. Genossen des Achterkollegiums, ebenso an die Gen. Vyšinskij und Zorin.

\section{Dokument 60}

RGASPI, f. 82, op. 2, d. 1042, S.78, 18.3. 1952

Ignat'ev: Trägt vor, dass der Vorsitzende der Sozialistischen Partei Österreichs (SPÖ), Schärf, im September 1951 der Parteiführung die Beschlüsse des Rates der „Sozialistischen Internationalen" mitteilte, der im Dezember 1951 in Brüssel abgehalten wurde. Schärf erklärte, dass die „Sozialistische Internationale“ prinzipiell für „die Verteidigung Europas gegen die UdSSR und ihre Verbündeten“ eintrete. Im Zusammenhang damit empfahl der Rat der „Internationalen“ allen sozialistischen Parteien unter allen Umständen für die die „Verteidigung" und Rüstung betreffenden Posten der Staatshaushalte zu stimmen. Nach der Erklärung Schärfs wies der Rat der „Internationalen“ die USA auf die Notwendigkeit der Entfaltung der Propaganda unter den Parteimitgliedern und Wählern hin, um von ihnen Unterstützung in der Remilitarisierung zu erringen. Schärf informierte die Führung der SPÖ darüber hinaus über den Beschluss des Rates bezüglich der Gründung der „Internationalen Hilfsorganisation für Arbeiter". Dieser Organisation wurde die Aufgabe gestellt, Emigranten, die „gezwungen sind, Zuflucht im Ausland zu suchen“, Hilfe zu erweisen.

Erging an Gen. Malenkov und Zorin.

\section{Dokument 61}

RGASPI, f. 82, op. 2, d. 1042, S. 82, 19.3.1952

Zorin: Trägt vor, dass entsprechend einer noch am 14. September 1951 ergangenen Mitteilung des französischen Botschafters in Washington, Bonnet, an das Außenministerium Frankreichs während der Erörterung der österreichischen Frage am 13. September durch die Außenminister der USA, Englands und Frankreichs, Acheson vorschlug, auf der nächsten Sitzung der Sonderbeauftragten für den österreichischen [Staats]vertrag die „Kurz“Variante des Vertrages, die alle früher im Zuge der Verhandlungen gemachten Zugeständnisse der Westmächte an die Sowjetunion annullierte, vorzubringen. Das Ziel dieses amerikanischen Vorschlages bestand nach den Worten Bonnets darin, die sowjetische Regierung in eine „schwierige Lage“ zu versetzen. Morrison bestand damals darauf, sich mit der Verwirklichung des amerikanischen Planes nicht zu beeilen. Wie der Vorsitzende der Österreichischen Volkspartei, Raab, im engen Kreis im September 1951 mitteilte, versprachen ihm die Amerikaner, in den nächsten Monaten „Österreich von den Russen zu erlösen“ und es in das System des Nordatlantikbündnisses einzubeziehen. Nach der Meinung der Amerikaner zeugt, wie Raab sagte, „die schwache Reaktion der UdSSR im Zusammenhang mit dem japanischen Vertrag“ davon, dass die Sowjetunion nicht wegen Österreich einen Krieg beginnen will. Raab wies ferner darauf hin, dass die Amerikaner bis zu diesem Zeitpunkt in Österreich „eine starke Regierung“ haben möchten, die fähig ist, „passiven Widerstand“ gegen die Anordnungen der sowjetischen Besatzungsmacht zu leisten. Bis Ende 1951 wurde 
der amerikanische Vorschlag zur Frage des Österreichvertrages endgültig zwischen den drei Westmächten abgestimmt gebracht, danach schlugen sie auch vor, am 21.Januar d. J. die nächste Konferenz der 4 Sonderbeauftragten einzuberufen, in der Absicht, auf dieser Konferenz die „Kurz"-Variante des Vertrages einzubringen. Die Regierungen der Westmächte legten bei der Übergabe der Note zum Österreichvertrag Eile an den Tag: ihre Botschafter in Moskau versuchten beharrlich, einen Empfang im Außenministerium der UdSSR ausgerechnet am 13. März, also sofort nach der Veröffentlichung der sowjetischen Note über die Grundlagen eines Friedensvertrages mit Deutschland, zu erreichen. Mit ihrer Note zum Österreichvertrag versuchten die Westmächte, die Aufmerksamkeit der öffentlichen Meinung in der Welt von der neuen wichtigen Initiative der UdSSR in der deutschen Frage abzulenken. Gen. Zorin brachte seine Meinung zum Ausdruck, dass im Falle der Zurückweisung des Entwurfes des „Kurzvertrages“ durch die Sowjetunion die Westmächte gemeinsam mit der Übergabe der Österreichfrage an die UNO mit einer einseitigen Deklaration über die „Gewährung der Freiheit und Souveränität für Österreich“ auftreten könnten, der zufolge der Abzug ihrer Truppen vom Territorium Österreichs den Abzug der sowjetischen Besatzungstruppen bedingt.

Erging an alle Mitglieder des Achterkollegiums, ebenso an die Gen. Vyšinskij und Gromyko.

\section{Dokument 62}

RGASPI, f. 82, op. 2, d. 1042, S. 101, 31.3.1952

Ignat'ev: Teilt mit, dass der Führer der österreichischen „Demokratischen Union“ Dobretsberger im Gespräch mit dem Vorsitzenden der österreichischen Volkspartei, Raab, am 23. Februar d. J. erklärte, dass der Weg Österreichs „aufs Haar genau mit dem Weg Finnlands zusammenfallen muss und Raab ein zweiter Kekkonen werden muss. Hierfür sei ein Wechsel des Außenministers nötig, ein Abgang vom amerikanischen Kurs mittels Absage von Rohstofflieferungen für die Rüstung des Westens und ein Protest gegen den Bau von Flugplätzen in Salzburg. " Raab bat Dobretsberger, Vertretern des Außenministeriums der UdSSR in Moskau, wohin Dobretsberger zur internationalen Wirtschaftskonferenz fährt, mitzuteilen, dass es in der ÖVP eine Gruppe von Leuten gibt - Raab, Steinböck, Strommer und and. -, die den Weg der Neutralisierung Österreichs suchen, ohne es hierbei in ein Land der Volksdemokratie umzuwandeln. Raab erklärte, dass der Präsident Österreichs, Körner, ständig die Idee der Neutralisierung des Landes und der Notwendigkeit des Aufbaus eines gegenseitigen Verständnisses mit der UdSSR hervorhebt. Dobretsberger vertritt die feste Überzeugung, dass es in der ÖVP eine ,ständig anwachsende Gruppe von Funktionären gibt, die ein Ende des Kalten Krieges und einen Kompromiss mit der UdSSR will. Hierzu zählen Kristofic-Binder und die Mehrheit der Wiener und niederösterreichischen Industriellen.

Erging an die Gen. Malenkov und Vyšinskij. 


\section{Dokument 63}

RGASPI, f. 82, op. 2, d. 1115, S. 110, 12.5.1952

Kopie $^{104}$

Str. Geheim, Ex. Nr. 2

An Genossen I. V. Stalin

Am 9. Mai schickten die Botschaften der USA, Englands und Frankreichs an das Außenministerium der UdSSR identische Noten, in welchen sie die sowjetische Regierung bitten, „bei erster Möglichkeit ihren Standpunkt im Zusammenhang mit den Vorschlägen zur Österreichregelung“ mitzuteilen.

Gemeint ist der Vorschlag der drei Mächte in der Note vom 13. März d. J. über den sog. Kurzvertrag für Österreich.

Ich würde es für zielführend halten, auf die Note der Regierungen der drei Mächte vom 13. März über einen Kurzvertrag für Österreich sachlich zum gegenwärtigen Zeitpunkt keine Antwort zu geben, um nicht die Aufmerksamkeit hinsichtlich der Erörterung der deutschen Frage, die bekanntlich auch die Regierungen der USA, Englands und Frankreichs anstreben, zu schwächen.

Auf die Noten der Regierungen der drei Mächte vom 9. Mai [sollten] an die Botschaften der USA, Englands und Frankreichs in Moskau Antwortnoten formalen Charakters, deren Entwurf beiliegt, ${ }^{105}$ geschickt werden.

Beschlussentwurf liegt bei. ${ }^{106}$

Bitte zu prüfen.

A. Vyšinskij

\section{Mai 1952}

Für die Richtigkeit: [Unterschrift unleserlich]

Kopien ergingen an die Genossen Molotov, Malenkov, Berija, Mikojan, Kaganovič, Bulganin, Chruščev

347-VK

Abgedr. in 10 Ex. ${ }^{107}$

\section{Dokument 64}

RGASPI, f. 82, op. 2, d. 1042, S. 187, 29.5. 1952

Ignat'ev: Legt den gekürzten Text des Telegramms des Stellvertreters des französischen Hochkommissars in Österreich, Lalouette, an das Außenministerium Frankreichs vom 17. Mai d. J. zur Frage über die Verhandlungen des österreichischen Kanzlers Figl in London

\footnotetext{
104 Daneben ein durchgestrichenes handschriftliches Kreuz Molotovs. Auf der linken Seite der Verweis „Zu den Akten“.

105 Wird hier nicht abgedruckt.

106 Wird hier nicht abgedruckt.

107 Links unten Eingangsstempel: Sekretariat V. M. Molotov, 12. V. 1952, Eingangsnummer: 6327ss.
} 
im Mai d. J. vor. In dem Telegramm wird mitgeteilt, dass, nach den Worten des englischen Hochkommissars in Österreich, Caccia, der Figl nach London begleitet, Figl den Engländern folgende Fragen stellen wird: Über den Staatsvertrag. ${ }^{108}$ Figl bat die Regierung Großbritanniens weiter zusammen mit den Regierungen der USA und Frankreichs zu versuchen, den Abschluss des Österreichvertrages zu erreichen. Englische Politiker gaben Figl entsprechende Beteuerungen. Über das mögliche Herantreten Österreichs an die UNO ${ }^{109}$ Figl erklärte, dass, wenn die Verhandlungen über den Staatsvertrag wieder in eine Sackgasse führen, die österreichische Regierung beabsichtige, sich an die UNO zu wenden. Hierbei sagte er, dass sie dies vermutlich frühestens im Herbst d. J. umsetzen würde. Die englischen Vertreter verhielten sich hierzu angeblich ziemlich zurückhaltend. Sie wiesen auf die Schwierigkeiten bei der Wahl des geeigneten Moments für einen Appell an die UNO hin, ebenso darauf, dass dieser Appell eine entsprechende Reaktion seitens der UdSSR hervorrufen kann. Es wurde entschieden, dass die österreichische Regierung keinerlei Schritte in diese Richtung unternehmen wird, ohne sie mit den Vertretern der drei westlichen Länder abgestimmt zu haben.

Erging an die Gen. Malenkov, Vyšinskij und Zorin.

\section{Dokument 65}

RGASPI, f. 82, op. 2, d. 1043, S. 198, 5.6.1952

Zorin: Stellt einen Bericht „Über die Vorbereitung zur Gründung eines aggressiven militärisch-politischen Blocks auf dem Gebiet des Balkans“ vor. Zum Zwecke der Festigung eines antisowjetischen Aufmarschgebietes am Mittelmeer versuchen die Führungskreise der USA gegenwärtig, neben dem Kommando in Mittelost einen militär-politischen Block, der mit dem Nordatlantikbündnis verbunden ist, aus Jugoslawien, Griechenland und der Türkei zu schaffen, an dem auch Italien und Österreich beteiligt sein könnten. Der Plan zur Schaffung eines solchen Blocks wurde von den Amerikanern schon vor langem vorgeschlagen, die praktische Verwirklichung dieses Plans stieß aber auf anglo-amerikanische Unstimmigkeiten und auf Widersprüche unter den Mitgliedsländern des geplanten Blocks. Die Amerikaner streben danach, dass der geplante Block eng mit dem Nordatlantikbündnis verbunden ist und einen bestimmten Teil an allgemeinen Aufgaben dieses Bündnisses in südeuropäischer strategischer Richtung übernimmt, die Engländer hingegen sind daran interessiert, den jugoslawisch-griechisch-türkischen Block vor allem an das Kommando in Mittelost zu binden und das Militärpotential der Teilnehmer dieses Blockes zur Festigung des Zugangs zum Mittleren Osten zu nutzen. Die Engländer treten ebenso gegen die Absicht der Amerikaner auf, dem geplanten Block Spanien anzuschließen, weil sie fürchten, dass das zum Verlust der englischen Kontrolle über Gibraltar führen wird. Die nach dem Krieg entstandenen Spannungen in den Beziehungen zwischen Griechenland und Jugoslawien, Griechenland und der Türkei erwiesen sich ebenso als großes Hindernis auf dem Weg zur Schaffung eines militärisch-politischen Blocks auf dem Balkan. Der Kampf zwischen Italien und Jugoslawien um Triest verhinderte die Organisation von Verhandlungen über die Teilnahme Italiens an diesem Block. Indem die Amerikaner danach strebten, diese Hindernisse aus dem Weg zu räumen, unternehmen sie Maßnahmen zur Glättung der Gegensätze

108 Im Original unterstrichen.

${ }^{109}$ Im Original unterstrichen. 
zwischen den vorgesehenen Mitgliedern des Blocks. Den Amerikanern gelang es, eine politische und wirtschaftliche Annäherung zwischen Griechenland und Jugoslawien und ebenso zwischen Griechenland und der Türkei zu erreichen. Auch die jugoslawisch-türkischen Beziehungen festigten sich. Dies erlaubte den Amerikanern, Anfang d. J. zur Organisation dreiseitiger griechisch-türkisch-jugoslawischer Verhandlungen überzugehen. Die Frage der Gründung des jugoslawisch-griechisch-türkischen Blocks wurde während des Aufenthaltes der griechischen Regierungsdelegation in Ankara (Februar d. J.), bei den Verhandlungen der türkischen Regierungsdelegation in Athen (Mai d. J.) und beim Besuch Eisenhowers im März in Griechenland und der Türkei erörtert. Die Hauptaufgabe der Verhandlungen zwischen den Mittelmeerländern ist die Suche nach einer Form, Jugoslawien in den geplanten Block einzubeziehen. Die Schwierigkeit für die Amerikaner bei dieser Aufgabe besteht darin, dass ein direkter Einschluss Jugoslawiens in die aggressive Union mit Griechenland und der Türkei zu einer endgültigen Sprengung der Position der TitoClique innerhalb des Landes führen könnte, was für die Amerikaner nicht wünschenswert ist.

Erging an Gen. Stalin und die and. Genossen des Achterkollegiums, ebenso an die Gen. Suslov, Vyšinskij, Grigor'jan, Bogomolov und Puškin.

\section{Dokument 66}

RGASPI, f. 82, op. 2, d. 1043, S. 200, 7.6.1952

Ignat'ev: Trägt vor, dass die Führer der Österreichischen Volkspartei in ihren Reden am 24. April d. J. auf der Konferenz der zentralen Organe der ÖVP die innenpolitische Lage des Landes äußerst negativ skizziert haben. So erklärte der Vorsitzende der Partei, Raab, dass „die innenpolitische Lage Österreichs noch nie so labil war wie jetzt“. Raab erklärte, dass die ÖVP alle nötigen Maßnahmen treffen muss, um die Macht in ihren Händen zu halten, wozu sie vor allem ihren Einfluss auf die Massen mittels der Heranziehung verschiedener reaktionärer Organisationen und besonders der Geistlichkeit und ehemaliger Nazis an ihre Seite stärken. Nach der Meinung Raabs muss die Partei die Propaganda von Grund auf ändern und berücksichtigen, dass „die Angstpropaganda vor der Volksdemokratie“ nicht mehr populär ist. Raab erklärte, dass „wir in keinem Fall fürchten dürfen, gegen die Amerikaner aufzutreten, weil sie sich erstens ebenso wie die anderen in der Österreichfrage nicht von der Stelle bewegen, und zweitens müssen wir die vorhandenen Sympathien in Österreich für Russland berücksichtigen“.

Erging an die Gen. Malenkov und Vyšinskij.

\section{Dokument 67}

RGASPI, f. 82, op. 2, d. 1043, S. 215, 18.6.1952

Zorin: Trägt vor, dass in der Position der österreichischen Regierung zur Frage des Österreichvertrages in der letzten Zeit Veränderungen vor sich gingen. Die österreichische Regierung hatte früher ihre Zustimmung zu dem Vertragsentwurf, der als Resultat der vierseitigen Verhandlungen vorbereitet worden war, gegeben. Nach der Veröffentlichung der "gekürzten “ Variante des Vertrages im März d. J. nahmen österreichische Staatsmänner davon Abstand, ihre Meinung zum Gehalt dieser Variante kundzutun. Dies rief die Unzufriedenheit 
der Amerikaner hervor, die forderten, dass die österreichische Regierung offiziell die "gekürzte" Variante des Vertrages unterstütze. Am 2. April trat Außenminister Gruber im Parlament auf und unterstützte lediglich in mittelbarer Form die "gekürzte" Variante. Die Wendung in der Taktik der österreichischen Regierung, die offensichtlich von den Amerikanern inspiriert wurde, ging im Mai vor sich, während einer Reise Figls, der mit einer Reihe von Erklärungen bedingungslos die "gekürzte“ Variante des Vertrages guthieß. Er unterstrich, dass, wenn die UdSSR Verhandlungen auf der Grundlage der "gekürzten" Variante nicht zustimmt, Österreich auf die Überantwortung der Österreichfrage an die UNO bestehen werde. Der Übergang der österreichischen Regierung zur offenen Unterstützung der ,gekürzten" Variante verfolgt offensichtlich das Ziel, einen Boden für weitere separate Tätigkeiten der Amerikaner in der Österreichfrage vorzubereiten. Nach den vorliegenden Angaben trifft der amerikanische Plan auf einige Einwände seitens der Engländer. Insbesondere die Engländer halten es für unmöglich, die Österreichfrage an die UNO zu übergeben.

Erging an die Gen. Vyšinskij und Puškin.

\section{Dokument 68}

RGASPI, f. 82, op. 2, d. 1043, S. 236, 1.7.1952

Ignat'ev: Trägt die Übersetzung der Mitteilung des politischen Vertreters Österreichs in der UdSSR, Bischoff, vom 20. Mai d. J., adressiert an den Außenminister Österreichs, Gruber, vor, in der es heißt, dass Gen. Zorin auf einem Empfang in der schwedischen Botschaft auf die Bemerkung des schwedischen Botschafters darüber, dass Figl Geld in Amerika suche, zur Antwort gab: „Das ist seine persönliche Angelegenheit. Aber das, was er sagt, ist eine öffentliche Angelegenheit." Bischoff antwortete, dass erstmals seit Beginn der Erklärung des „Kalten Krieges“ ein verantwortlicher Mitarbeiter des Außenministeriums so offen seine kritischen Bemerkungen bezüglich der Auftritte eines Mitglieds der österreichischen Regierung zum Ausdruck brachte.

Erging nur an Gen. Molotov.

\section{Dokument 69}

RGASPI, f. 82, op. 2, d. 1043, S. 268, 29.7.1952

Ignat'ev: Trägt Mitteilungen über Aussagen des Vorsitzenden der Führungsorgane der Österreichischen Volkspartei, Raab, auf der Sitzung der Parteiführung am 21.Juni d. J. vor. Raab erklärte, dass der „Kalte Krieg“ zwischen der UdSSR und den USA gegenwärtig einen „Kulminationspunkt“ erreicht und Österreich ein „propagandistischer Vorposten der USA“ in diesem Krieg geworden ist. Nach der Meinung Raabs ist die Forderung der Amerikaner über den Abschluss des „Kurz-Staatsvertrages“ und über die Aufnahme Österreichs in die UNO „billiges Hilfsmittel“, das die USA gegen die UdSSR benutzen. Raab bemerkte, dass er nach der Rückkehr des Kanzlers aus den USA mit ihm über die amerikanische Österreichpolitik gesprochen habe und er den Eindruck gewann, dass „die Amerikaner nicht wüssten, was sie wollen“. Nach der Meinung Raabs existieren im Kreis der politischen Verantwortlichen, die die Außenpolitik der USA bestimmen, einige Gruppen. Die stärkste von ihnen ist die Gruppe, die mit den „amerikanischen Juden“ verbunden ist. Diese Gruppe „ist an der Durchführung einer Kriegshysterie interessiert“, auch wenn sie keinen echten Krieg 
wünschen, da sie an der Vorbereitung eines neuen Krieges mehr verdient, als sie an einem Krieg selbst verdienen kann“. Die zweite Gruppe besteht aus den Befürwortern Eisenhowers, die zum Ziel hat, ihren Kandidaten als Präsidenten durchzubringen und dann einen Krieg zu beginnen“. Raab bemerkte ferner, dass es in den USA auch eine Gruppe von Isolationisten gibt, deren Kraft gegenwärtig nicht einzuschätzen ist. Die Vertreter dieser Gruppe sind organisatorisch schwach geeint, ihre Politik findet aber Unterstützung bei den Gewerkschaftsmitgliedern. Abschließend wies Raab darauf hin, dass bis zur Klärung der Präsidentenwahlergebnisse in den USA die führenden Funktionäre Österreichs den „Anschein erwecken “werden, dass sie alle Anweisungen der Amerikaner erfüllen, in Wirklichkeit aber „die Durchführung aller großen Maßnahmen auf eine spätere Zeit verschieben, wenn klar ist, wer in den USA siegt".

Erging an die Gen. Malenkov, Berija, Bulganin, Vyšinskij.

\section{Dokument 70}

RGASPI, f. 82, op. 2, d. 1043, S. 282, 10.8. 1952

Ignat'ev: Legt Übersetzungen von Dokumenten vor, die vom politischen Vertreter Österreichs in der UdSSR, Bischoff, an seinen Außenminister gerichtet wurden.

In einer Mitteilung vom 19. Februar d. J. kommentierte Bischoff den Misserfolg des amerikanischen Versuchs, die russische Emigration zu vereinen. Er merkte an, dass „die Emigration nichts anderes sein kann, als ein Geheimdienst jener, die mittels entsprechender Subventionen ihr wieder die Möglichkeit gegeben hat, zu existicren und ihre eigene „Politik“ zu entfalten. ["]

In der Mitteilung vom 17. Februar d. J. wies Bischoff betreffs der Erklärung Kirks, des zum Repräsentanten des „Amerikanischen Komitees zur Befreiung der Völker Russlands“ gewählten ehemaligen amerikanischen Botschafters, über die „antibolschewistischen Positionen der überwältigenden Mehrheit des russischen Volkes“ darauf hin, dass Kirk diese Meinung „erst nach seiner Abreise aus der UdSSR gewinnen konnte, möglicherweise in Paris, wo er in der Funktion eines ,Experten' der US-Delegation bei der UNO hinzugezogen wurde, oder in den USA selbst“. Die Frage einschätzend, mit welchem Ziel Führungskreise der USA Erklärungen über „die Unhaltbarkeit der inneren Lage der UdSSR “ abgeben, zieht Bischoff den Schluss, dass „sie auf diese Weise agieren, wenn sie propagandistisch einen aggressiven Angriffskrieg gegen die Sowjetunion vorbereiten wollen, der für einen bestimmten Moment vorgesehen ist und dem einfachen Mann in der westlichen Welt als moralisch berechtigt dargestellt wird und gleichzeitig nicht mit besonderen Opfern und Schwierigkeiten verbunden ist".

In der Mitteilung vom 5. April d. J. legt Bischoff sein Gespräch mit Radchakrishnan dar, der eben erst aus England zurückgekehrt ist, wo er Gespräche mit bedeutenden Politikern führte. Die Essenz dieser Gespräche war die Überzeugung davon, dass „die englische Regierung aufrichtig bestrebt ist, die internationale Atmosphäre zu entspannen, aber mit dem Pentagon kann man halt nichts machen“. „Das sich verbreitende Eingeständnis einer wachsenden Abhängigkeit Englands von einer solchen besorgniserregenden Politik Amerikas“, sagte Radchakrishnan, ,führt gemeinsam mit der erzwungenen Senkung des Lebensstandards im Land, die durch den Rüstungswettlauf hervorgerufen wird, zu einer Stärkung der antiamerikanischen Stimmung im englischen Volk, besonders unter der universitären Jugend und anderen Intelligenzschichten." 
Der Außenminister Österreichs, Gruber, teilte Bischoff in einem Brief am 28. April d. J. mit, dass das österreichische Außenministerium „aus gänzlich seriösen Quellen Hinweise erhalten hat, dass sich die Sowjetunion auf den 3. Weltkrieg vorbereitet und dass im Zusammenhang damit die berühmte Note in Bezug auf Deutschland, die vor allem als taktischer Zug im Kampf um die öffentliche Meinung in Deutschland zu sehen ist, sehr ernste Ziele verfolgt. Diese Meinung begründet sich auch mit den mit besonderer Energie durchgeführten Arbeiten zum Wiederaufbau der nach wie vor im zerstörten Zustand befindlichen Eisenbahnlinien und Straßen in den Gebieten eines möglichen Angriffs auf den Westen." Gruber erbat Bischoff um seine Meinung in der genannten Frage. Bischoff teilt in seiner Antwort am 10. Mai d. J. mit, dass von ihm „keine Hinweise darauf, dass die UdSSR die Absicht hat, einen aggressiven Krieg zu beginnen, bemerkt wurden“. Bischoff merkt an, dass „die Sowjetunion gegenwärtig verhältnismäßig weniger Rüstungsanstrengungen an den Tag legt als durchschnittlich während des Zeitraumes des III. Fünfjahresplans, gar nicht zu reden von dem Krieg von 1940, als der Anteil der Rüstung um weniger als ein Drittel das spezifische Gewicht der Militärausgaben in der Gegenwart überschritt“. Bischoff wies ferner daraufhin, dass „die Sowjetunion zur Erreichung des Kommunismus buchstäblich nichts von der kapitalistischen Welt braucht als die Erhaltung des Friedens“. In der Mitteilung vom 16. Mai d. J. informiert Bischoff darüber, dass „sich aus Beobachtungen, die von neutraler Seite in den allerletzten Wochen angestellt wurden, klar ergibt, dass in Polen, der Tschechoslowakei und Ungarn keine besondere militärische Tätigkeit festgestellt wurde“.

Erging an alle Mitglieder des Achterkollegiums.

\section{Dokument 71}

RGASPI, f. 82, op. 2, d. 1043, S. 286, 14.8.1952

Ignat'ev: Trägt vor, dass Anfang Juli d. J. Acheson seiner Auffassung nach von der österreichischen Regierung verlangte, die Gründung einer österreichischen Armee zu beschleunigen, um „das Vakuum zwischen Jugoslawien und Westdeutschland aufzufüllen“. Die österreichische Regierung gründete im Juli d. J. das „Komitee der Streitkräfte“, als dessen Vorsitzender der Staatssekretär des Innenministeriums, Graf, fungiert. Am 21.Juli d. J. fand im Innenministerium eine Konferenz der Chefs der Bundesländergendarmerieabteilungen statt, auf der beschlossen wurde: 1) Die Gendarmerie-Schulen, die den Bundesländergendarmerieabteilungen zur Verfügung stehen, und die Sonderformationen der Gendarmerie unter die Leitung des „Komitees der Streitkräfte“ zu übergeben; aus den Mannschaften dieser Schulen und Sonderformationen der Gendarmerie militärische Untereinheiten zu gründen, die Gendarmeriebataillone genannt werden; 2) die Gendarmeriebataillone ausschließlich mit amerikanischen Waffen zu bewaffnen.

Erging an Gen. Stalin und die and. Genossen des Achterkollegiums, ebenso an Gen. Vyšinskij.

\section{Dokument 72}

RGASPI, f. 82, op. 2, d. 1043, S. 288, 15.8. 1952

Ignat'ev: Trägt vor, dass Ende Juli d. J. das Außenministerium Frankreichs und das State Department Noten zur Frage über den österreichischen Staatsvertrag austauschten. Die 
Franzosen schlugen vor, dass die Frage des Vertrages von Ländern, die formal nicht an ihm interessiert sind und keine Mitglieder des Nordatlantikbündnisses sind, zur Prüfung in die UNO eingebracht wird, da anderenfalls „dies wie ein Manöver gegen die UdSSR aussehen kann“. Das State Department und das Außenministerium Frankreichs kamen zu folgendem Schluss: a) die Frage über den österreichischen Vertrag wird von Ländern, die formal nicht am Abschluss dieses Vertrages interessiert sind, zur Prüfung durch die Generalversammlung in der Form eines eigenen Tagesordnungspunktes eingebracht. Die Prüfung dieser Frage in der UNO hat „die Annahme einer Empfehlung der Generalversammlung, die der UdSSR, den USA, Großbritannien und Frankreich empfiehlt, die Verhandlungen zur Frage über den Abschluss des österreichischen Vertrages zu beschleunigen“, zum Ziel.

Erging an die Gen. Malenkov, Vyšinskij.

\section{Dokument 73}

RGASPI, f. 82, op. 2, d. 1043, S. 299, 23.8. 1952

Tugarinov (KI): Teilt mit, dass Brasilien und eine Reihe anderer kleiner Mitgliedsländer der UNO beabsichtigen, die Frage des österreichischen Vertrages auf die Tagesordnung der 7. Sitzung der UNO-Generalversammlung zu setzen. Tatsächlicher Initiator des Einbringens der österreichischen Frage in die UNO ist die Regierung der USA, die die Vorbereitung dieses Schrittes noch im März d.J. in Angriff nahm. Nach der Veröffentlichung der Note der drei Mächte an die Sowjetunion vom 13. März d. J. über den „Kurzvertrag“ forderten die Amerikaner von der österreichischen Regierung, dass sie erklärte, dass im Falle eines Ablehnens des Vorschlages der drei Mächte durch die Sowjetunion, die Österreichfrage an die UNO übergeben werden muss. Am 15. August d. J. erklärte nach der Veröffentlichung der sowjetischen Antwortnote zur Österreichfrage der stellvertretende Staatssekretär der USA, McDermott, offiziell, dass die Regierung der USA es für zielführend erachtet, die Österreichfrage an die UNO zu übergeben. Noch im Mai d. J. trat die Regierung der USA mit der englischen und französischen Regierung zur Frage über die Übergabe der Österreichfrage an die UNO in Verhandlungen. Die Engländer und Franzosen widersprachen zunächst dem amerikanischen Vorschlag. Unter amerikanischem Druck jedoch erklärten sich die Regierungen Englands und Frankreichs einverstanden, ihre Einwände gegen den amerikanischen Plan aufzuheben. Hierbei bestanden sie darauf, dass ein Appell an die UNO nicht von den drei Westmächten ausgehen solle, sondern von Ländern, die nicht unmittelbar am Abschluss des österreichischen Vertrages interessiert sind. Die Amerikaner erklärten sich angeblich mit dieser Forderung einverstanden. Die Regierung Österreichs erklärte unter dem Druck der USA offiziell die Nützlichkeit der Einbringung der Österreichfrage in die UNO. Zugleich sind die österreichischen Führungskreise ernsthaft beunruhigt über mögliche Folgen von separaten Aktionen der Westmächte in der Österreichfrage für Österreich. Nach inoffiziellen Mitteilungen erklärte Figl während der Verhandlungen in den USA im Mai d. J., dass sich Österreich eher einverstanden erklärt, „die Lasten einer vierfachen Besatzung zu tragen, als in zwei Teile gespalten zu werden“.

Erging an Gen. Stalin und die and. Genossen des Achterkollegiums, ebenso an die Gen. Suslov, Vyšinskij, Grigor'jan, Puškin, Podcerob. 


\section{Dokument 74}

RGASPI, f. 82, op. 2, d. 1043, S. 314, 2.9.1952

Rumjancev (KI): Legt eine „Übersicht internationaler Ereignisse im August d. J.“ vor. [...] ${ }^{110}$ Bezüglich der sowjetischen Note vom 23. August d. J. zur deutschen Frage ${ }^{111}$ heißt es im Überblick, dass die in dieser Note enthaltenen Vorschläge die Regierungen der USA, Englands und Frankreichs in eine schwierige Lage versetzt haben und die Positionen der Befürworter einer Lösung der deutschen Frage auf vierseitiger Ebene bestärkt haben. Fast alle amerikanischen Zeitungen und am meisten die reaktionäre Presse der westlichen Länder versuchen den Eindruck einer Übereinstimmung zwischen den USA, England und Frankreich in der Frage der Einschätzung der Note zu vermitteln. Diese Zeitungen bekräftigen, dass die Note „propagandistischen“" Charakter trägt, „nichts Neues beinhaltet" und deshalb von den Westmächten abgewiesen werden muss. Viele bourgeoise Zeitungen Englands und Frankreichs unterstreichen jedoch, dass eine Ablehnung der Prüfung der sowjetischen Vorschläge ein „großer Fehler“ wäre. In Westdeutschland unterstützten einige Bundestagsabgeordnete, darunter Mitglieder der Bonner Regierungskoalition, unter dem Druck der öffentlichen Meinung die Vorschläge der UdSSR.

Über die sowjetische Note vom 14. August zur Frage des Staatsvertrages mit Österreich heißt es in der Übersicht, dass die Regierung der USA den Vorschlag der sowjetischen Regierung über die Wiederaufnahme vierseitiger Verhandlungen zu Österreich feindselig aufgenommen hat und auf der Notwendigkeit der Übergabe der österreichischen Frage an die UNO besteht. Erst unter Druck der Amerikaner erklärten sich auch die Regierungen Englands und Frankreichs einverstanden, den Plan der Übergabe der österreichischen Frage an die UNO zu unterstützen, auch wenn sie Zweifel an der Zweckmäßigkeit dieser Fragestellung an die UNO zum Ausdruck brachten.

110 Erster Absatz über Reaktionen der ausländischen Presse auf den Beschluss des Plenums des ZK der VKP(b) über die Einberufung des 19. Parteitages der VKP(b). Zweiter Absatz über die Reaktionen der „bourgeoisen Presse“ auf die Ankunft der chinesischen Regierungsdelegation in der UdSSR.

111 Im Original unterstrichen. 